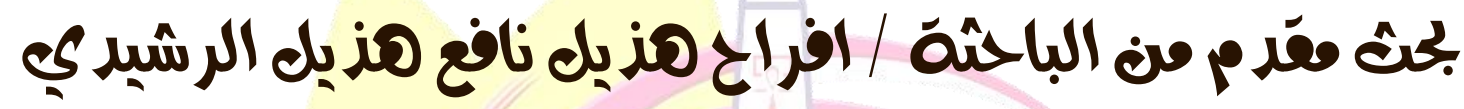

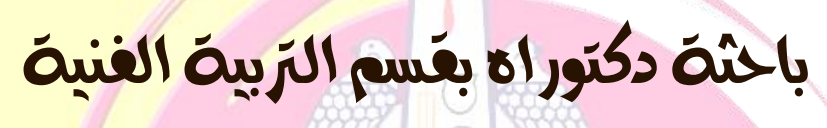$$
\text { كلبة الزبية النوعبة }
$$

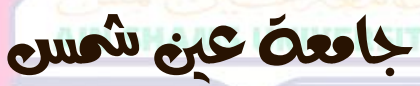

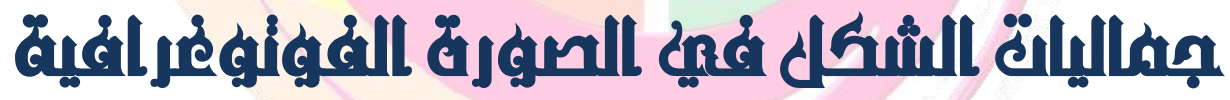

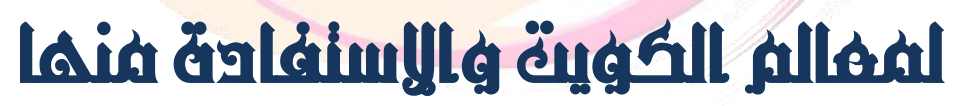

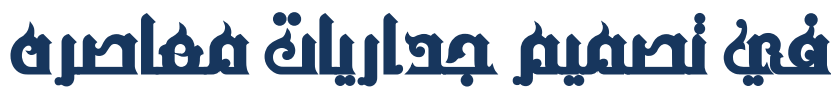


تثهد المسيرة الثقافية والفنية للمجتمعات عبر العصور صورا من التحول الثقافي، والتغير

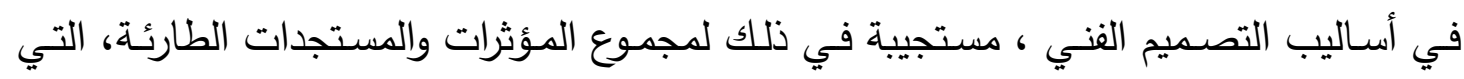

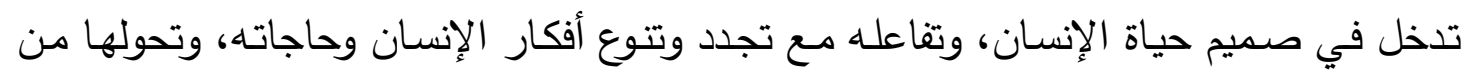

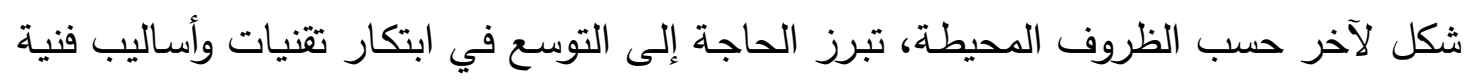
مستحدثة، تلبي طموحات الإنسان، وتغطي احتياجاته في التصميم.

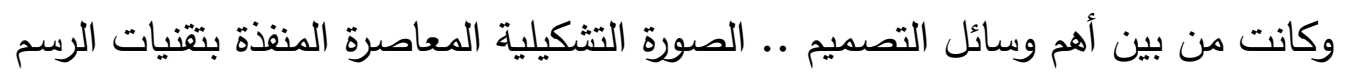

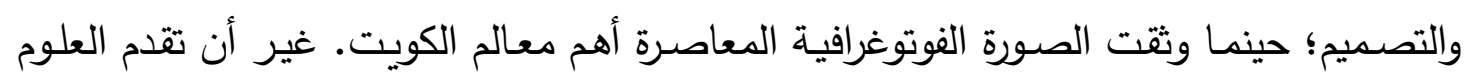

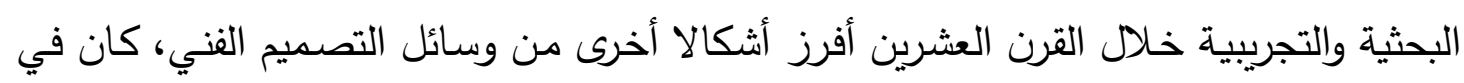

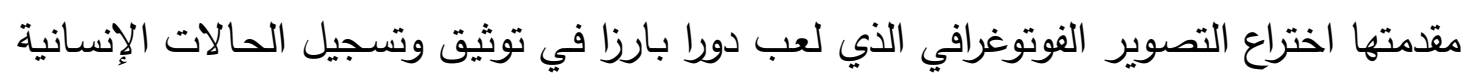

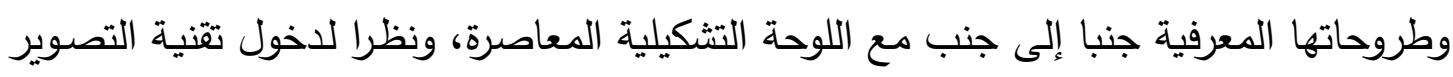

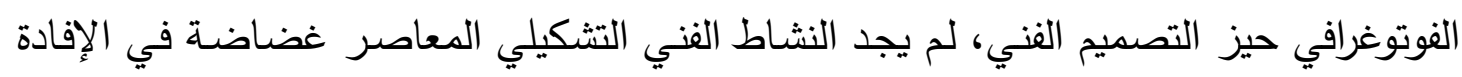

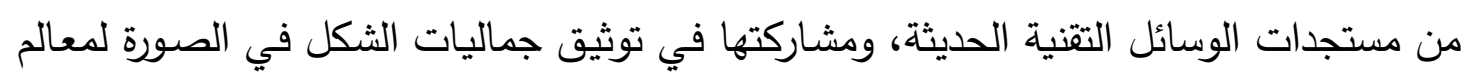

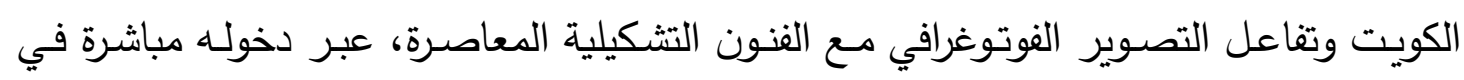

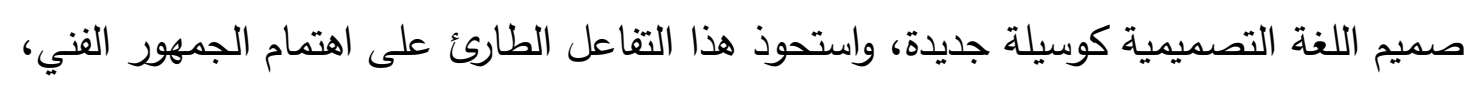

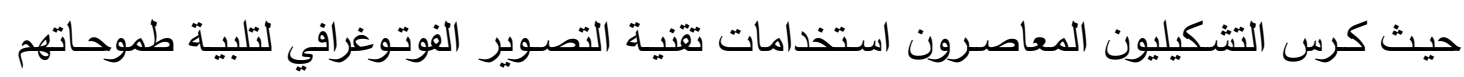
وحاجاتهم الجديدة للتعبير الفني، وذلك من خلال كثف ودراسة وتحليل زوايا مبتكرة في المنظور البصري، تعالج مساحة بصرية وفرتها تلك التقنية الجديدة، وعملت على إغناء لغة التصميم الفني وقدمت للفنانين والجمهور آفاقا ورؤى مستقبلية لم تكن متاحة من قبل.

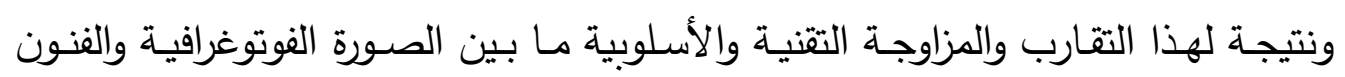
التشكيلية المعاصرة، ظهرت أثكال وأساليب فنية متعددة، تصف هذا التقارب وتكثف عنف عن وسائل

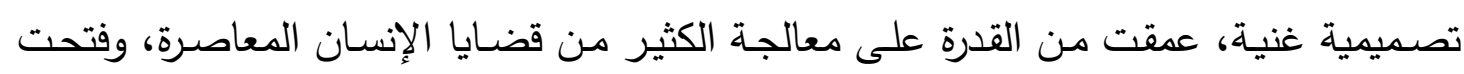

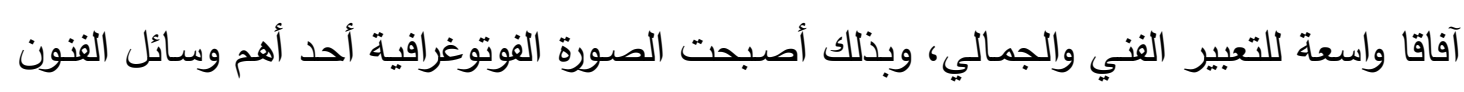

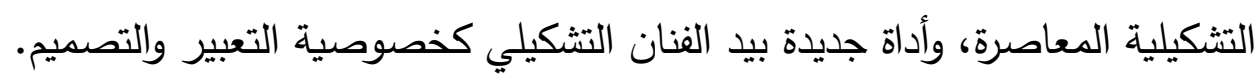
مشكلة البحث : تتحدد مشكلة البحث في التساؤل التالي: ما مدى إمكانية الإفادة من جماليات

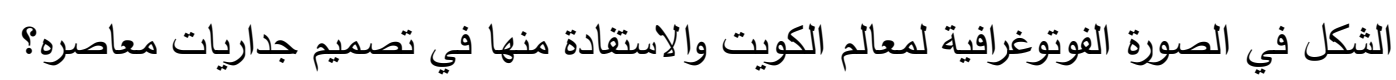


هدف البحث: الكثف عن جماليات الثكل في الصورة الفوتوغرافية لمعالم الكويت والاستفادة

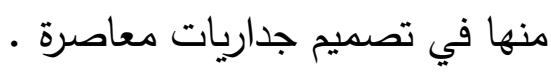
فرض البحث: توجد علاقة إيجابية بين جماليات الشكل في الصورة الفوتوغرافية لـعالم الكويت وتصميم جداريات معاصره

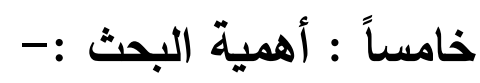
ا ـ إخراج منتج فني يلبي احتياجات المجتمع الكويتي. r. تنوع التصديمات تبعاً لتنوع الصور الفوتوغرافية المتاحة.

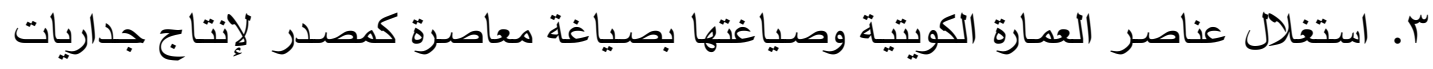
فنية.

ـ. كسب خبرة الرؤية الفنية المعاصرة ذات الامتداد التاريخي .

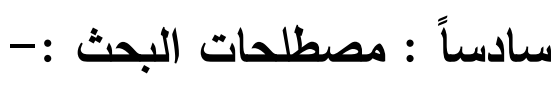

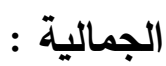

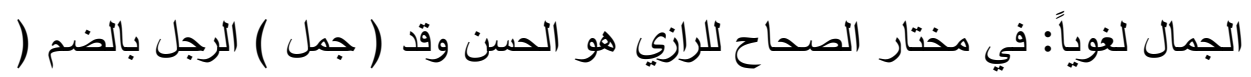

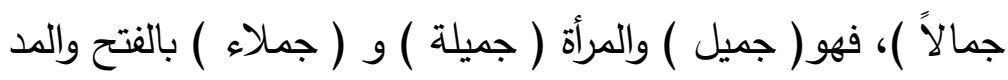

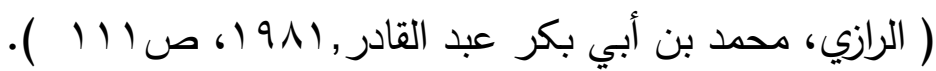

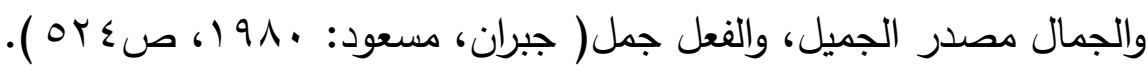

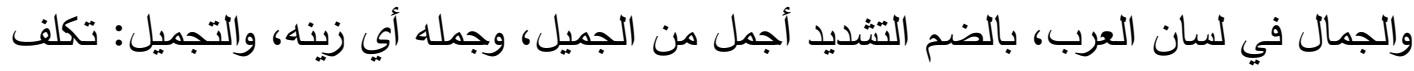

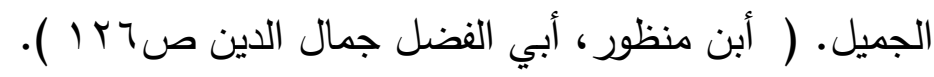

وفي القاموس المحيط الجمال: هو ما حسن من الخلق والخلق( الزاوي، الطاهر أحد ).

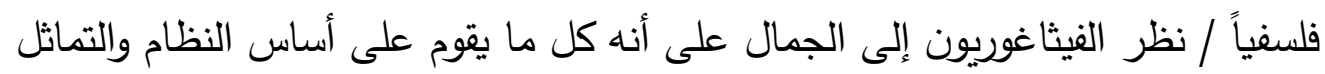

$$
\text { والانسجام(عبد الحميد، شاكر . . 199 , صمث ). }
$$

وعند ( أفلاطون ) و (أرسطو ) هو التناسب والائتلاف والنظام والكمال في كل الموجودات، في

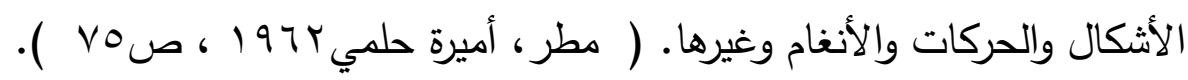

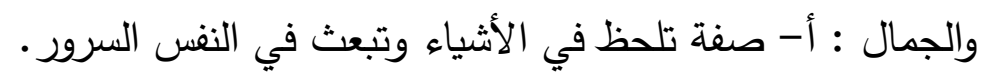
ب- بوجه خاص أحد القيم الثلاث التي تؤلف مبحث التئن القيم العليا، وهي عند المثاليين صفة قائمة في طبيعة الثيء، ومن ثم هي ثابتة لا تتغير ، ويصبح الثيء جميلاً قيما في ذاته 
بصرف النظر عن ظروف من يصدر الحكم، وعند الطبيعيين فالجمال اصطلاح عرفته مجموعة

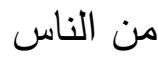
وعند الفيلسوف الجمالي ( جورج سانتيانا ) فالجمال: هو قيمة إيجابية نابعة من طبيعة الثيء

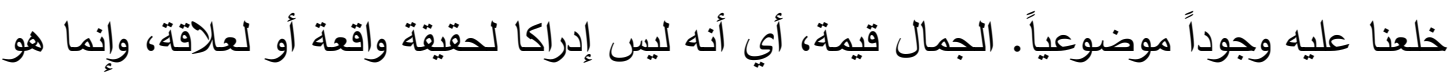

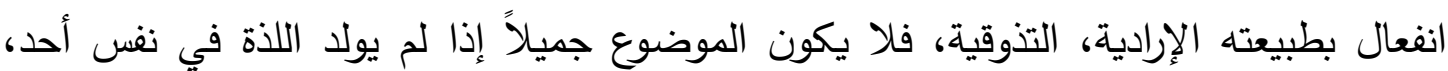

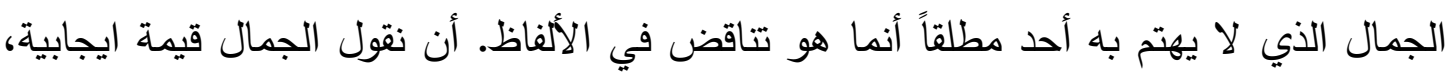
أي أنه إحساس بوجود سيء حسن أو بانعدام شيء حسن ( في حالة القبح )، وهو ليس أبداً

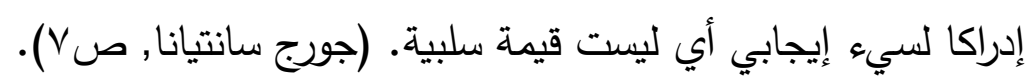
الجمالية: ترد بمعنى علم الجمال حسب معجم الرائد

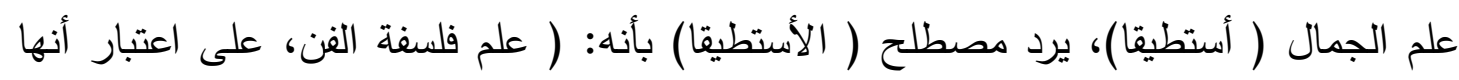

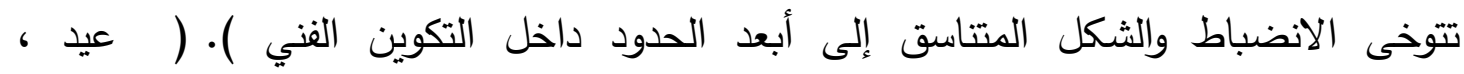

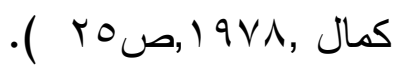
علم الجمال ( الأستطيقا): علم القوانين العامة التي تبحث في دراسة المشكلات التي يخلفها التفكير والتأمل وتثيرها الأعمال والإنجازات الفنية، من خلال استيعابها للواقع والتعبير عنه بصورة فنية، وهو العلم الذي يشكل جوهر الفن ومعاييره وقواعده وأشكاله وعلاقته وتذوقه، وإدراكه واستيعاب تأريخ تكوين أحكام عقليـة نقديـة وإدراكـات حسية، ولا يمكن فصـل مفهوم الجمـال والجميل في الحديث عن علم الجمال، لأنهــا محور القيم والخبرة الجماليـة التي تدرسهـا (

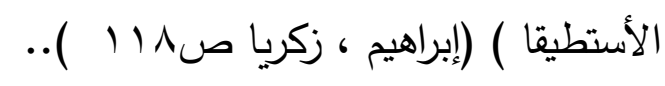

\section{الصورة الفوتوغرافية :}

التصوير الفوتوغرافي وتحول الدفاهيم شكلت بدايات القرن الماضي حقبة تحولات واسعة في

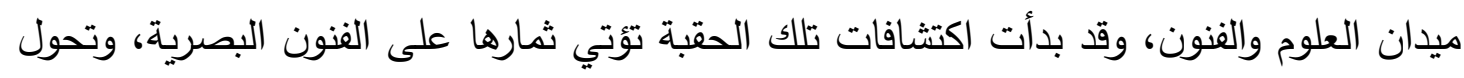

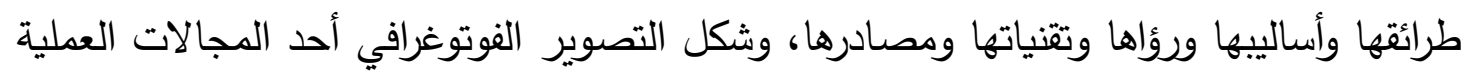

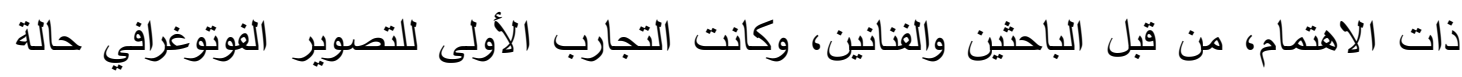

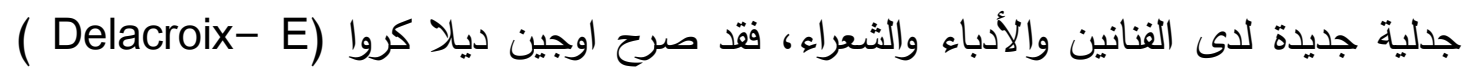

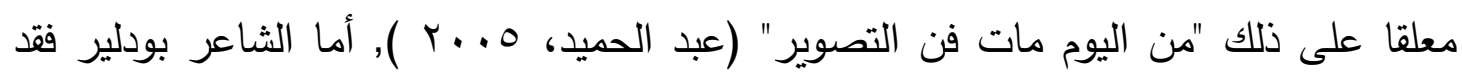

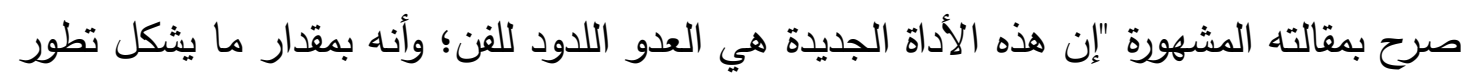


التصوير الفوتوغرافي نتاجا للتقدم التكنولوجي يكون الثعر والتقدم مثل رجلين طموحين يكره

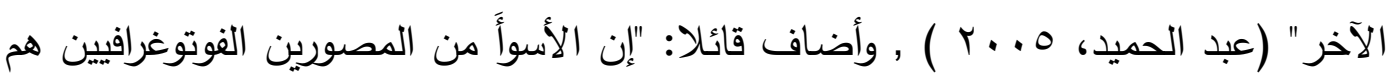

الرسامون الحديثون المتأثرون بالتصوير الفوتوغرافي"، وقال رودان: "إن الفنان هو الصادق، أما

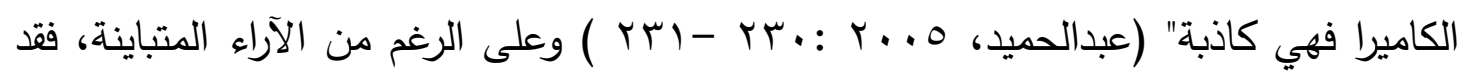
تطور التصوير الفوتوغرافي بشكل متسارع، أدى حضوره إلى تتنية مكتملة لإنتاج الصور، والتعامل مع الواقع بكل الظروف والمتغيرات، وبسرعة كبيرة جدا. تصميم جداريات :

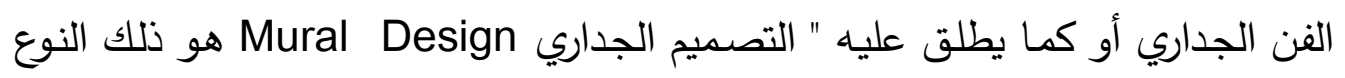

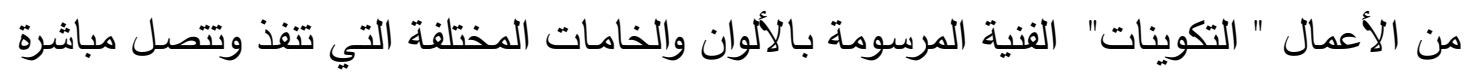

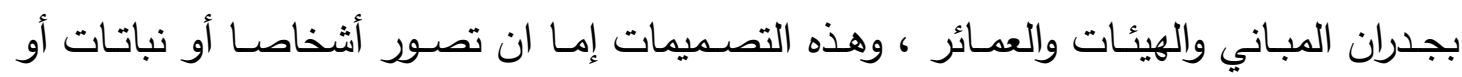

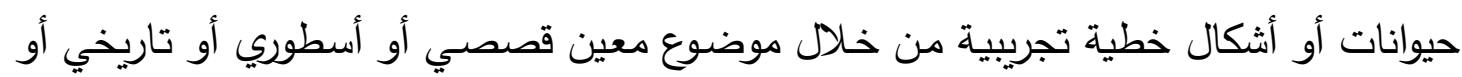

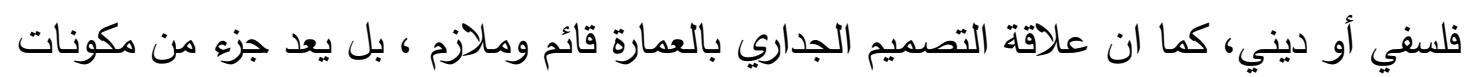

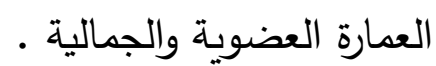
ولقد استثمر الفنانين كل معطيات التكنولوجيا وتوظيفها في الجداريات الفنية عبر مراحل تاريخ الفن المختلفة ، ونظراً لطبيعة الفن وارتباطه بالثقافة المعاصرة ، وقد اتضح ذلك بصورة جلية وواضحة في فنون ما بعد الحداثة لما واكبته من تطور تكنولوجي في الوسائط المتعددة من الخامات والأدوات المختلفة ، كما ودخلت الجداريات في كثير من الاتجاهات الفنية في فنون ما بعد الحداثة كالفن التفاعلي ، مثال ذلك ما نشاهده واضحاً في الجدارية الرقمية (تدفق السير )

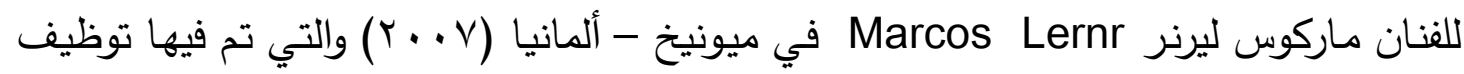

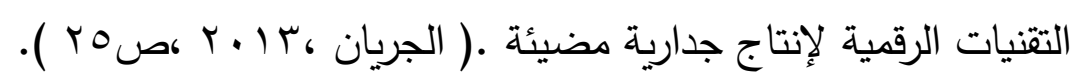

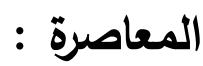

الأصول اللغوية (عاصر -عاصر فلأناً- لجأ إلية ولأذبه وعاش معه في عصر واحد )

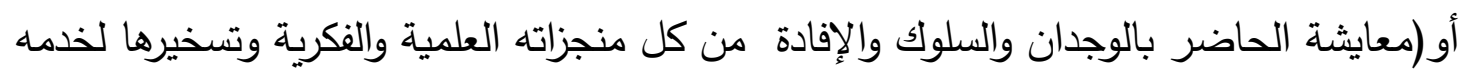
الأنسان ورقيه) ( في المعجم الوسيط ). 
وهي قدرة تعبيريه خلاقة تحمل في داخلها مدلولاتها الزمنية، فالتجديد قدرة تتسم بالفاعلية والحركة تجاه كل ما هو جامد وثبوتي متصف بالتصدي والتقوقع والتراجع. " المعاصرة "(هي النشاط الإنساني الذي يحدث حولنا في يومنا الحاضر ومنها إنتاج التصاوير والتماثيل والفخار ورسوم الحضر وغيرها من المواضيع المتثابهة لها باعتبارها مواضيع فنيه ). (

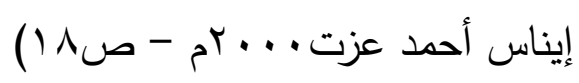
سابعاً : الاراسات السابقة:

هنالك شح وندرة في الدراسات العربية التي تتاولت الفن الرقمي في مجال التصميم الفني

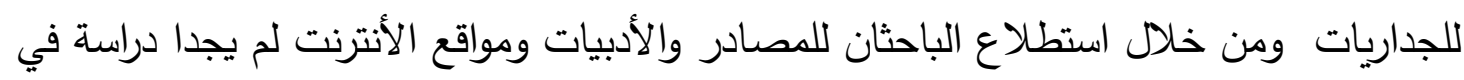

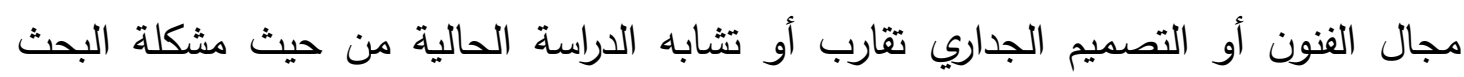

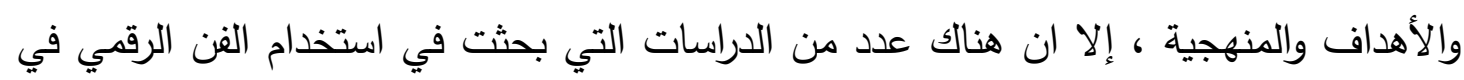

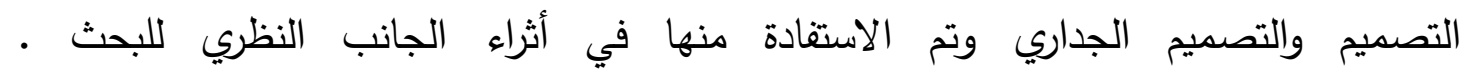
ومن بين هذه الدراسات : ا. دراسة: أمجد عبد السلام عيد ، " الفن الرقمي كوسيط تقني لأثراء التصميم التثكيلي وأثره

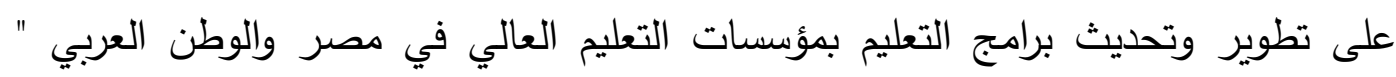

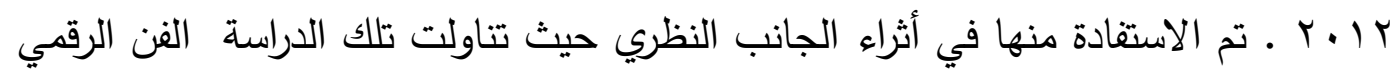

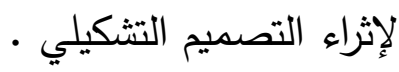
r. و دراسة : ندى بنت سعود بن سعد الجريان ،"رؤية معاصرة لفن الجداريات في ضوء التقنية

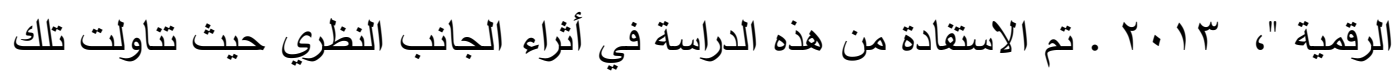

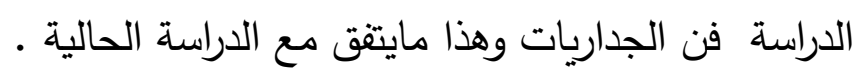

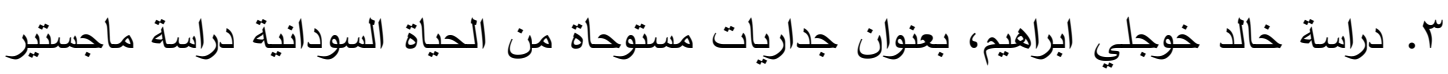

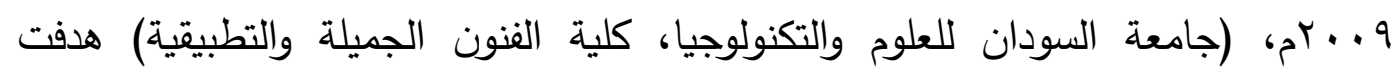
الدراسة للبحث في أصول التصوير الجداري السوداني وتطوير مفهومه العام مجال. واستلهام

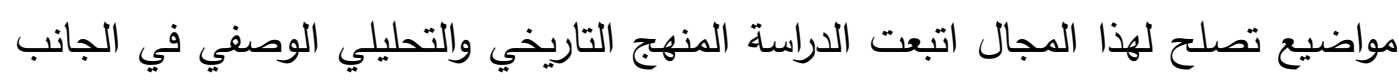
النظري والتجريبي التحليلي في الدراسة التطبيقية. ومن النتائج التي توصل لهاب لهاب الدارس. اتساع المفهوم العام بالنسبة للتصوير الجداري والذي يشمل جوانب معمارية وتثكيلية كثيرة

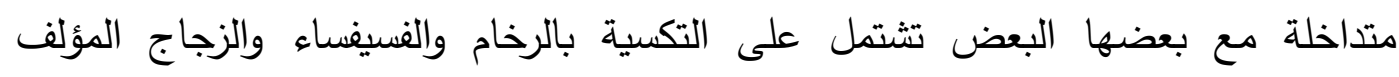
بالرصاص والحديد والكلادن .واتضح أن الفنان السوداني قد استفاد من الخامات والتقنيات 
والظروف البيئية والاجتماعية والدينية المحيطة به في ابتكار وتصميم أساليب وتقنيات مختلفة باختلاف البيئة والثقافة المعمارية حسب المنطقة وذلك بالبحث والتجريب عبر تقنيات

$$
\text { مبتكرة أنتجها الفنان السوداني. }
$$

ـ. ودراسة عمر كمال الدين الطيب، بعنوان القيم الجمالية في زخارف العمارة الثعبية النوبية

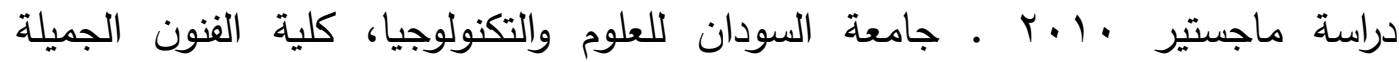
والتطبيقية .(تناول الباحث في هذه الدراسة منطقة النوبة شمال السودان في عمارتها الثعبية

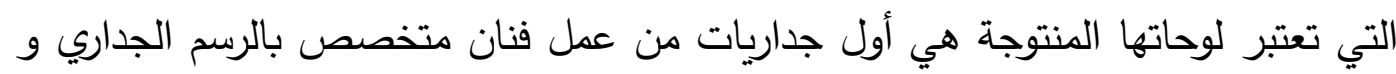

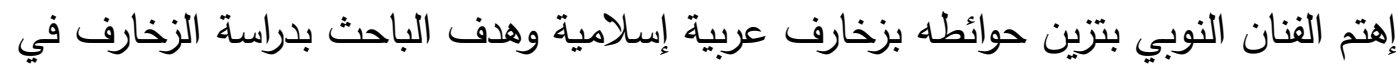

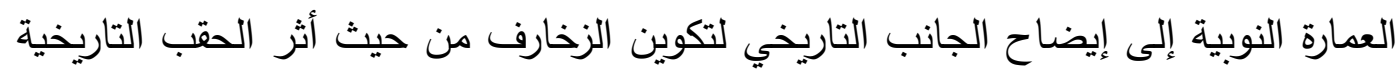

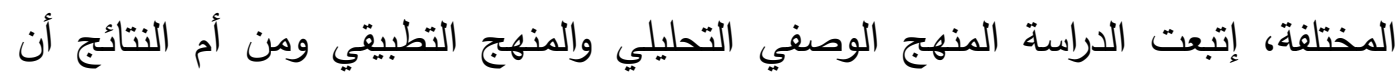

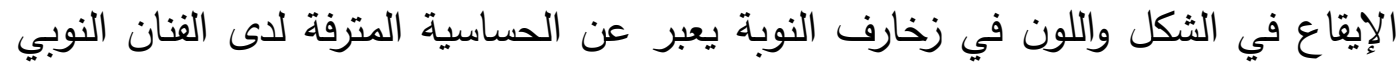

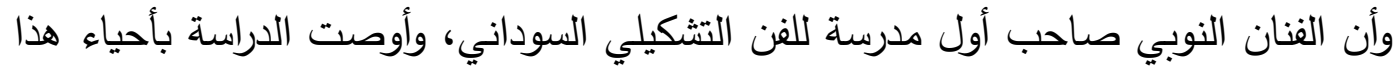

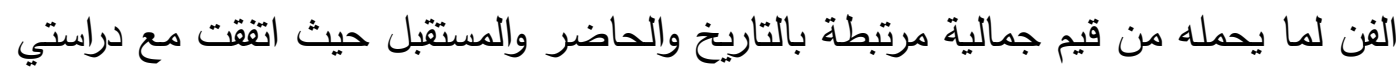

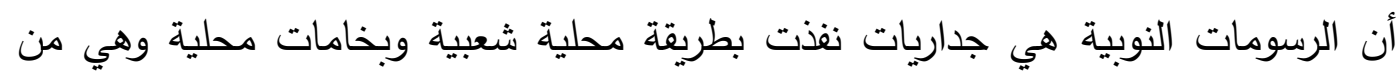

$$
\text { الجداريات الأولى في مفهوم العمل الجداري. }
$$

๑. دراسة معتصم حسين عمر، ماجستير 9. ج. بعنوان دراسة اللوحة الجدارية التوثيقية لثخصيات تاريخية من مدينة ام درمان. (جامعة السودان للعلوم والتكنولوجيا، كلية الفنون

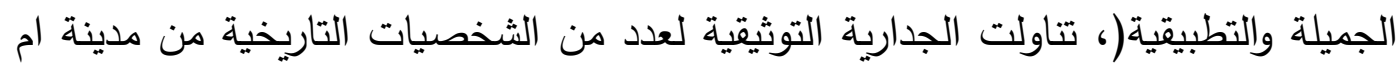

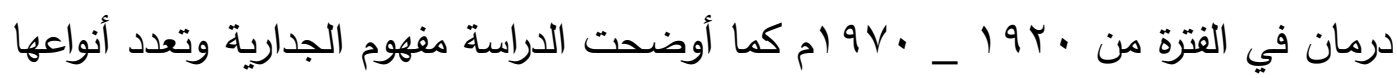

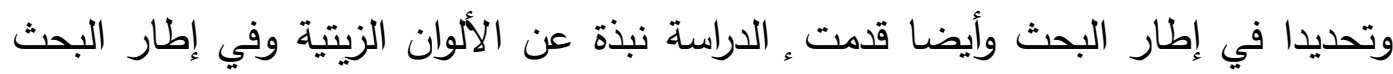

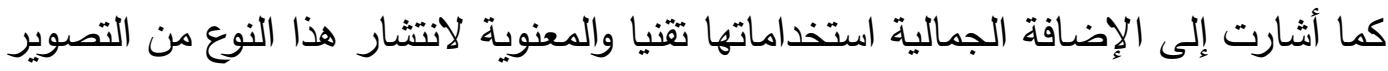

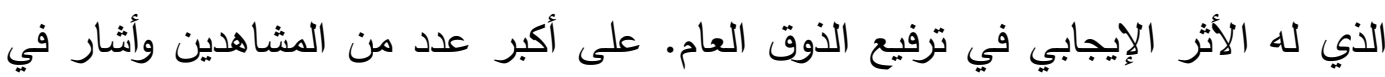

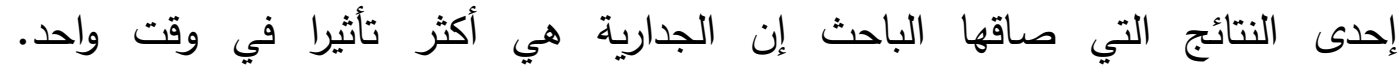
7. دراسة خالد خوجلي ابراهيم بعنوان تقنيات التصوير الجداري وتطبيقاتها على العمارة دراسة التهاتي

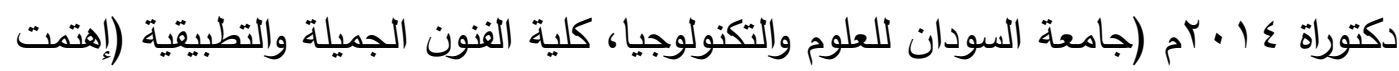

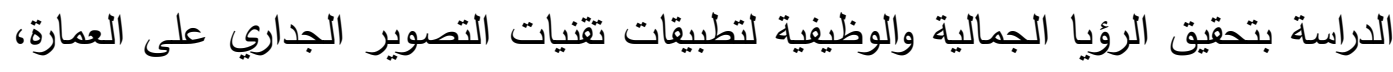

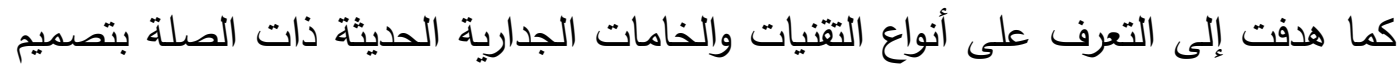


وتنفيذ اللوحة الجدارية. ومن أهم النتائج التي صاغها الباحث هي. إن اللوحة الجدارية

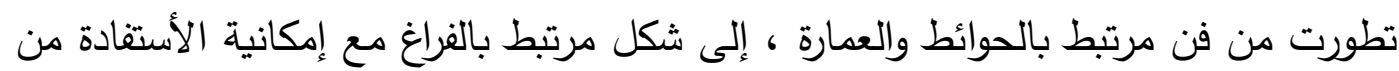

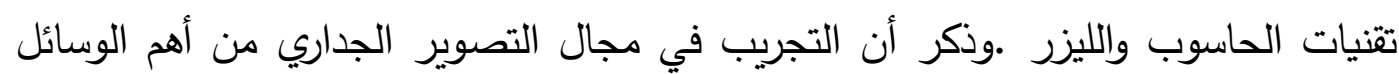

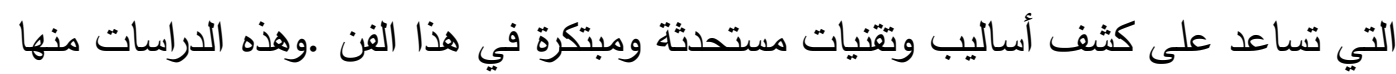
ما تناولت موضوع التصوير الجداري وتقنياته التقليدية والحديثة .

ثامناً : منهجية البحث :- البه

تتتبع الدراسة الحالية المنهج الوصفي لما يتعلق بالإطار النظري , والمنهج الثبه التجريبي فيما يتعلق بالجانب التطبيقي , وذلك من خلال الخطوات التالية :

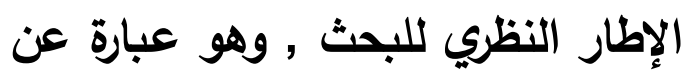
ا ـ دراسة جماليات الثكل في الصورة الفوتوغرافية لمعالم الكويت. r. ب. دراسة تصميم الجداريات المعاصرة. r. عرض للدراسات المرتبطة بمجال البحث بهدف التعرف على نتائجها وبيان مدى الاستفادة منها في مجال التصميم الجداري. ـ. عرض بعض أعمال الباحثة في الفن الجداري. الجانب التطبيقي , وهو عبارة عن هراسة تحليلية لبعض معالم الكويت .

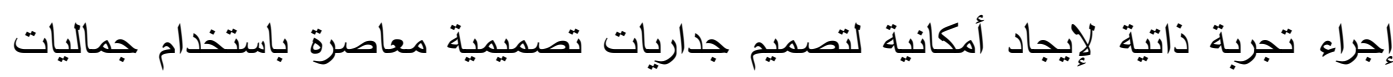

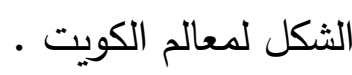
الخامات والأدوات : الخعال

$$
\begin{aligned}
& 1 \text { ـ الوان أكريليك وبعض الخامات الأخرى . } \\
& \text { r ـ الاستعانة ببرنامج (الفوتوشوب) }
\end{aligned}
$$

\section{الاطار النظري}

هنالك ارتباط بين الإنسان والفن، لكونه "إدراك عاطفي للحقيقة "( محمد زكى العشماوي الإي

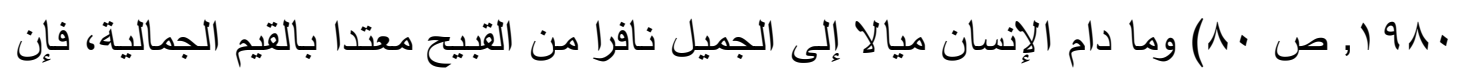

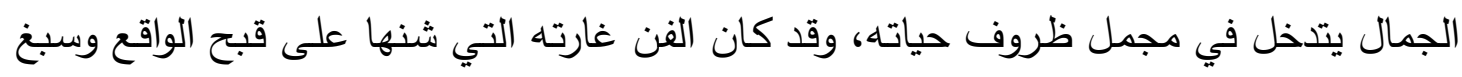
عليه الأبعاد الجمالية، ليصبح (الفن) "قدرة على توليد الجمال ومهارة في استحداث متعة جمالية" 
ولقد تعددت المواقف واختلفت الآراء في تفسير مفهوم الجمال؛ وذلك لتباين المعارف والمنطلقات الفلسفية والعلمية التي حاولت الإحاطة بمظهره. فنظر إليه أفلاطون Platon" على أنه ملكة مثالية لا يمكن إدراكه بالمعارف الحسية،

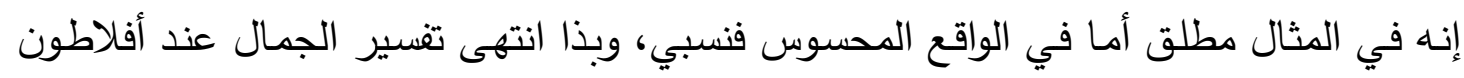

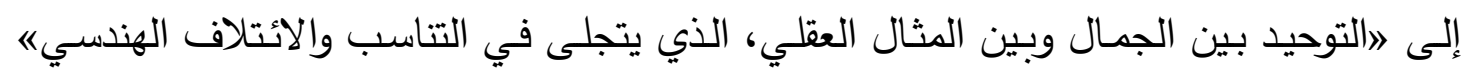

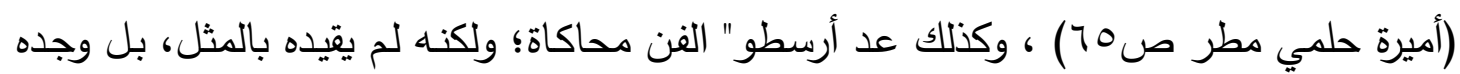

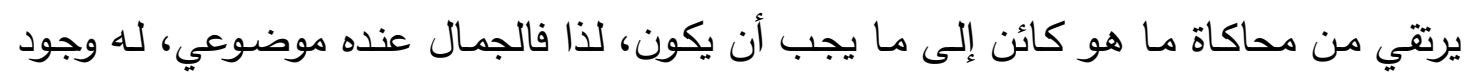

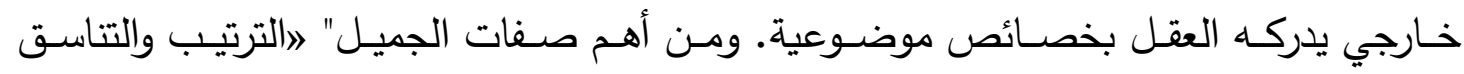

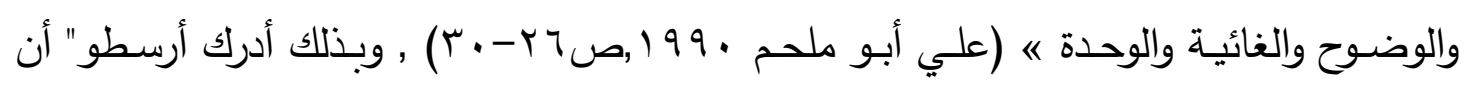
الجمال سمو رؤيوي وارتقاء على الواقع.

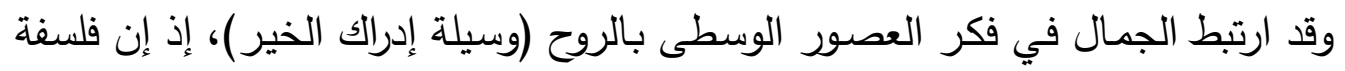

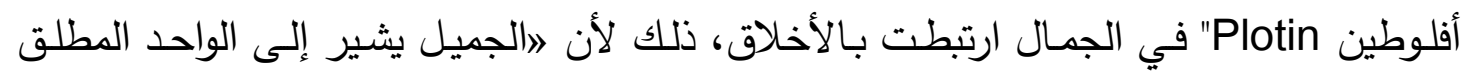

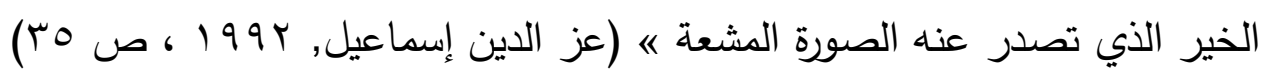

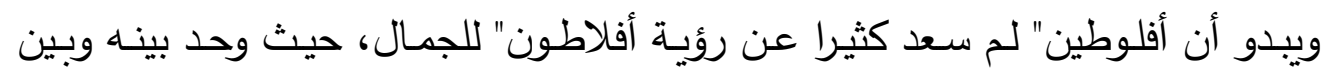

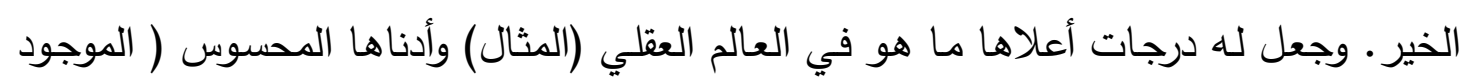
في الطبيعة).

ومع بداية العصر الحديث، أضحى الجمال بعيدا عن الأخلاق والمنفعة والمثالية وارتبط

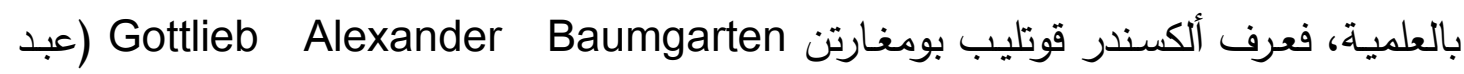

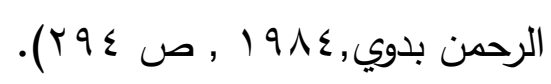

علم الجمال في كتابه تأملات فلسفية ب " Aesthetics" الأستطيقا (ذا ويعود هذا

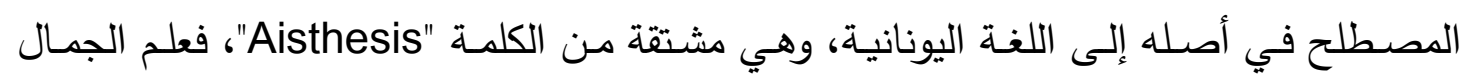

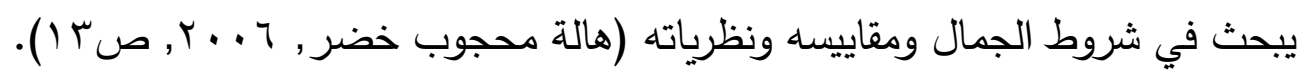

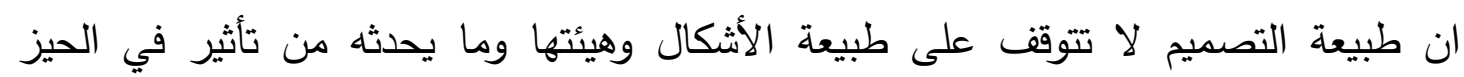

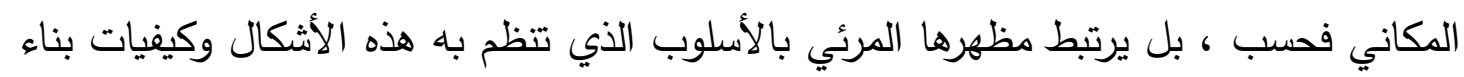

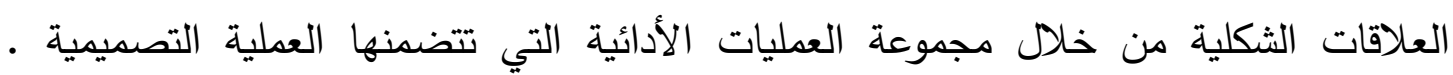


كما ان حيوية العناصر والمفردات التثكيلية تتشأ بين الأشكال عن طريق أسلوب تتظيمها ، فلأشكال مقاومة تتبعث منها ، فيبدو لنا الإحساس بالضغط والمقاومة التي تبديها الأثكال

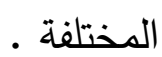

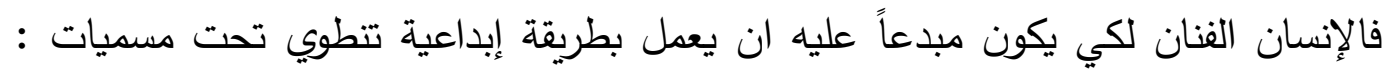

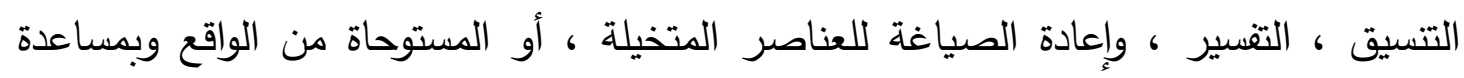

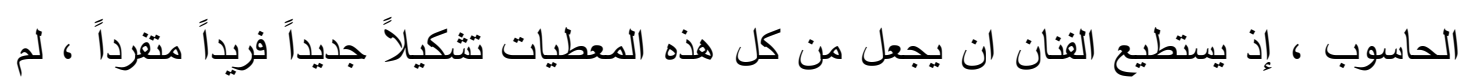
يكن مألوفاً ، ولم يسبق إليه أحد.

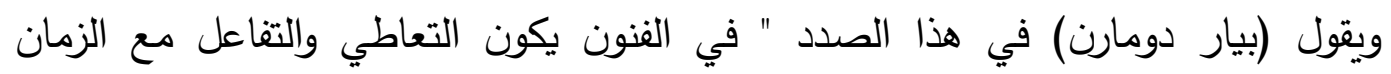

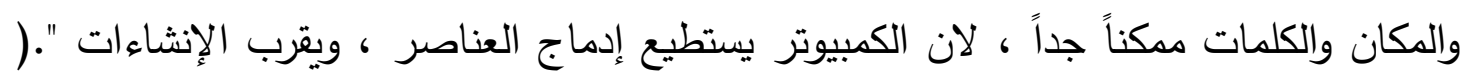

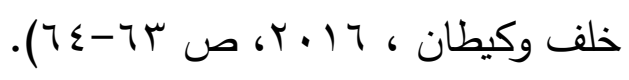

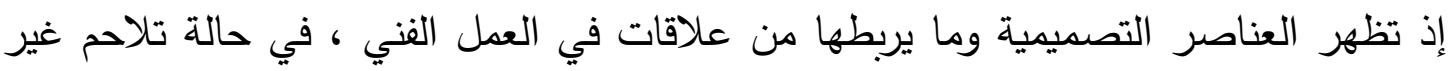
قابل للانفصال وفي وحدة تجمعها معاً ، فالمتلقي للعمل التثكيلي ليس باستطاعته أثناء تلقي

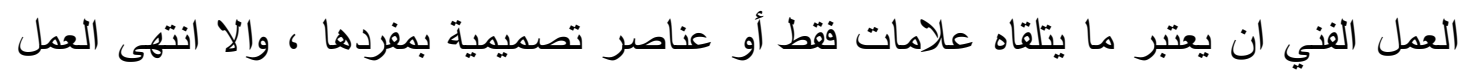

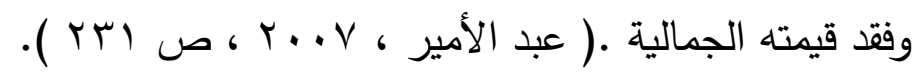

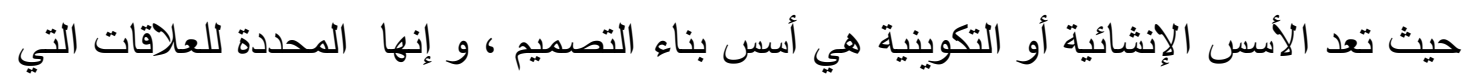

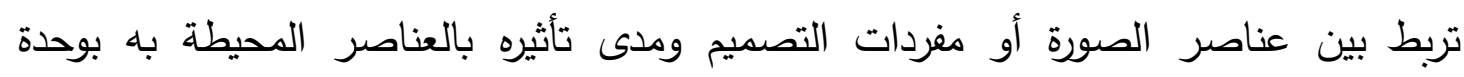

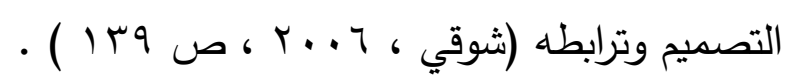
"كلما أرتبط العمل الفني بالعصر الذي أنتج فيه ، كلما أعطاه ذلك قيمة وأصبح إِنعاساً لمقومات عصرة، وترتبط المعاصرة بالأبداع، من حيث إبتكار أثكال سلوكية تتكيف مع البيأئة البطاه

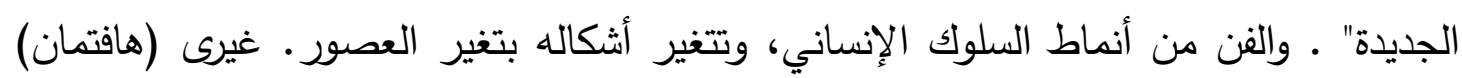
haftmann الأنسان والبيئة وتغبير مدركاته . ولقد تعددت منابع الرؤية في الفن المعاصر بحيث شملت أسباباً ومصادر كثيرة، بحيث تمثلت

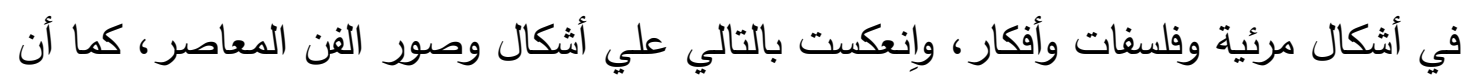

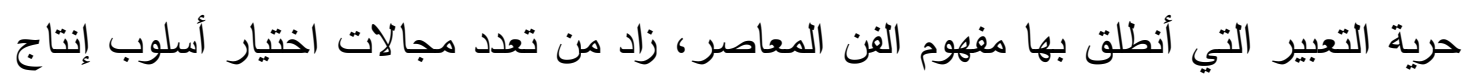
الفنون، ولعل هذا ما زاد الفنون المعاصرة ثراء وتتوعاً. 
وهناك تعريف (عزمي VY/ I SAV) لمعنى مفهوم المعاصرة، فقد قسمها إلى ثلاثة أقسام

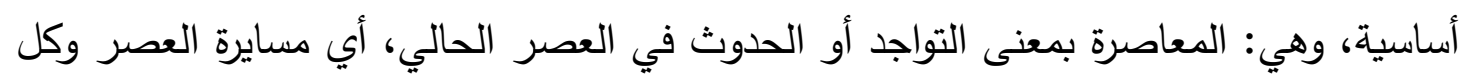

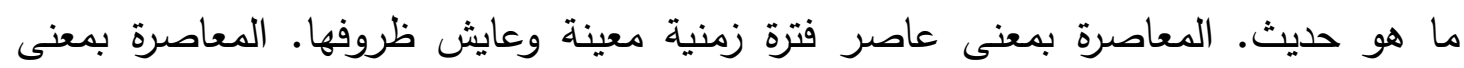

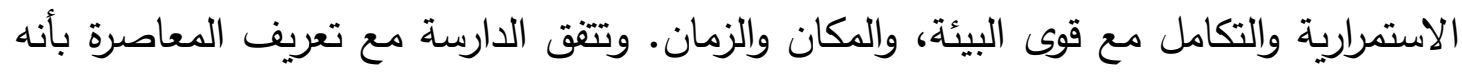

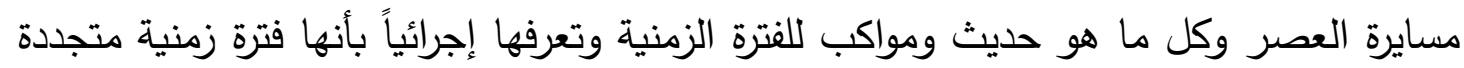

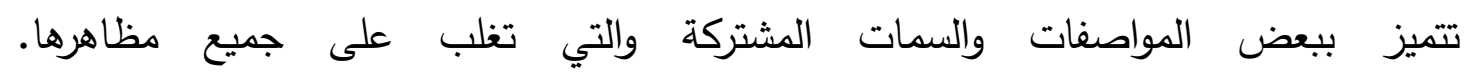
وفكرة المعاصرة عند (هربرت ريد) مشتقة من إنعكاس الثقافة الحديثة- أي أسلوب الحياه

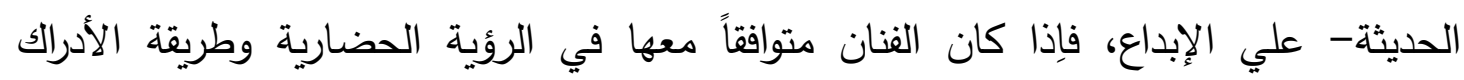
والتفكير تغير أسلوبه الإبداعي بما تقتضي الظروف الإبن المستحدثة بالحداثة .

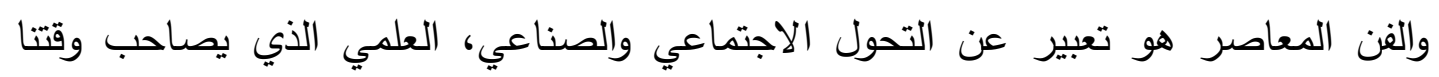

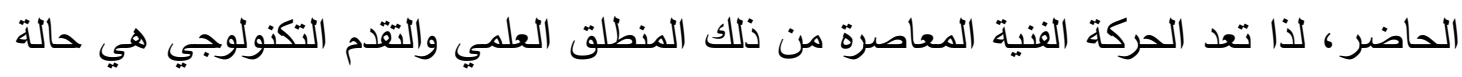

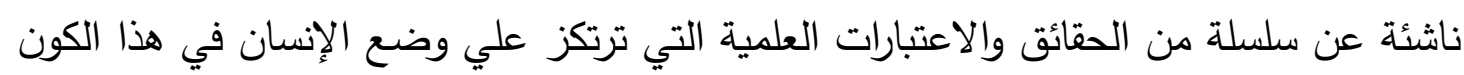

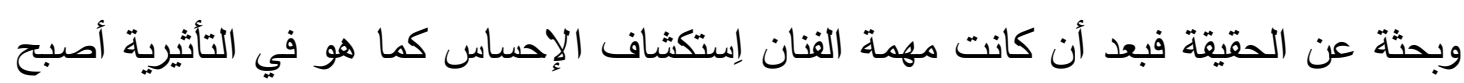

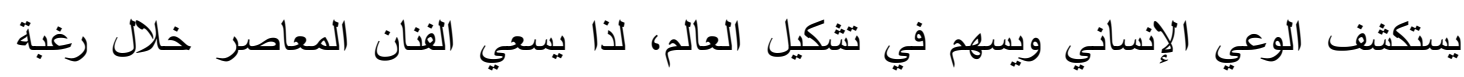

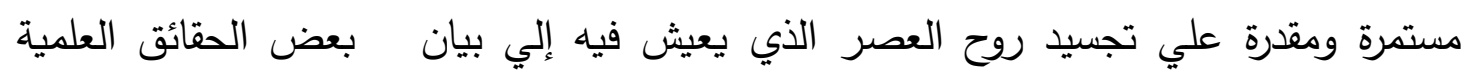
والفلسفية وتقديم إنتاجه الفني في صورة إبداعية تساعد علي التعرف علي حقيقة التشكيل

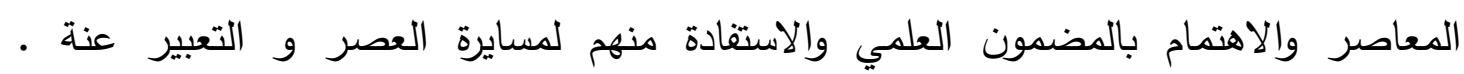
وهو إمتداد لما وصل إليه الفن الحديث من تحرر الفنان في إستخدام عناصر العمل الفني بشتي الطرق وأساليب الأداة الفني وأصبح الفن لا يتميز بأي سمات ظاهرية محددة بل يتميز بظهور إتجاهات متعددة ومتضاربة يغلب عليها الفردية حيث إتجهت الفنون نحو تحقيق الوجود الإنساني للفنان وشخصيته المتميزة .

ومن أهم معالم المعاصرة في القرن العشرين هي طبيعة العلاقة المعاصرة لأنه لا يلبي

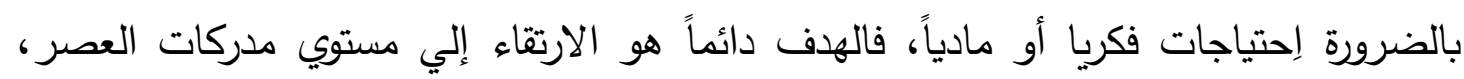

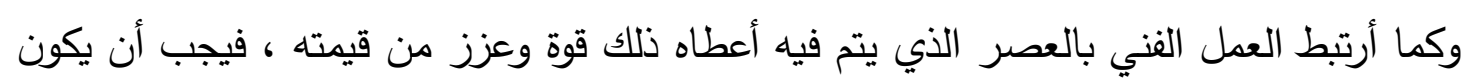

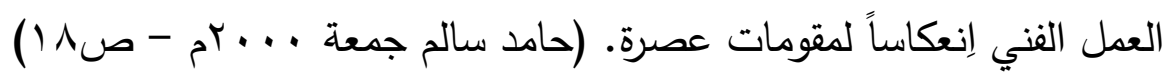


وفرت الوسائط التثكيلية التقليدية والفوتوغرافية المعاصرة نظما وانساقا جديدة تكاملية في أدوار التعبير عن المعاني والدلالات الإنسانية الرمزية للرؤية الفنية، وتوجيه المتلقي عبر وسائل ولئل

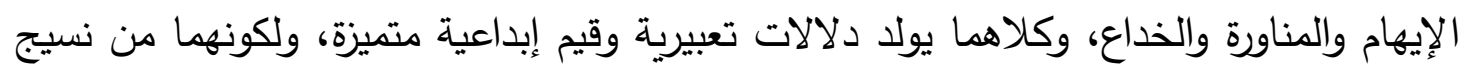

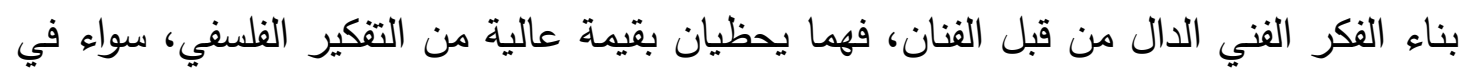
اللوحة التثكيلية أو التصوير الفوتوغرافي، وذلك عبر استعاراتهما المعدلة، محققة استجابة

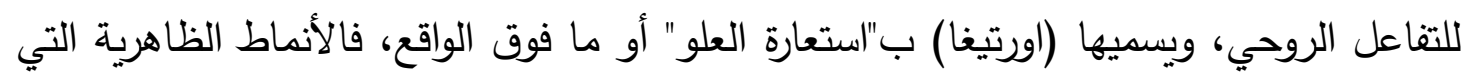

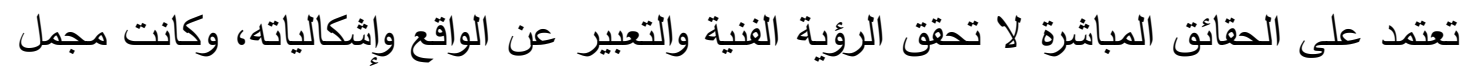
الحركات الفنية الحديثة، كالتعبيرية والتكعيبية والتجريدية والرمزية تحقيقا لاستعارة العلو (خوسيه

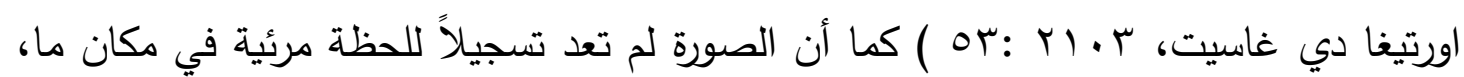

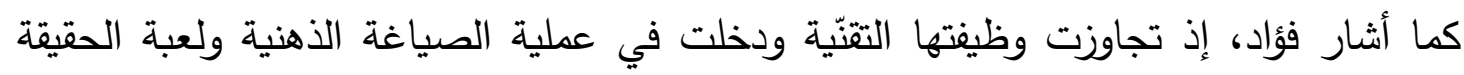

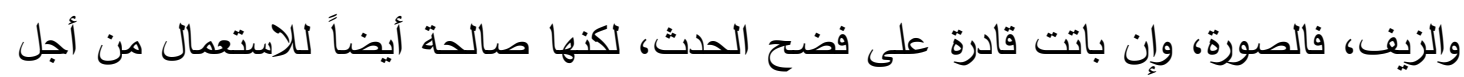

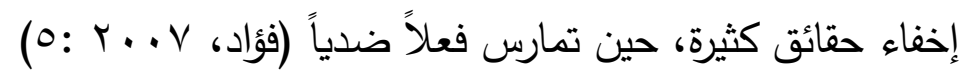
فرضت الطبيعة المناخية للكويت علي عمرانها القديم أن يجاري تلك فلك الطبيعة ويتاسب مع ما تفرضه من متطلبات مناسبة للعيش فيها ـ فكان من نتيجة ذلك أن تكونت أشكال معينة

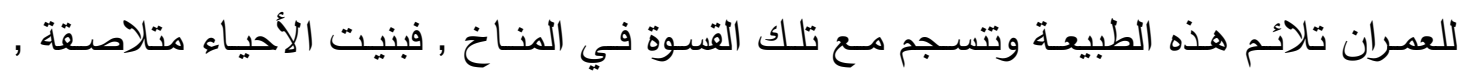
وفصلت بين المساكن مسافات صغيرة , إضـافة إلي تقارب جميع الأمكنة العامة التي يرتادها

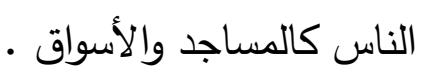
وتميز التطور العمراني في الكويت بالبطه في بدايته , ثم تسارع بشكل كبير مع تطور

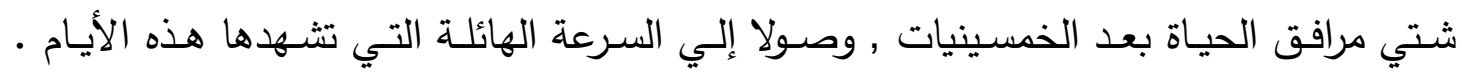

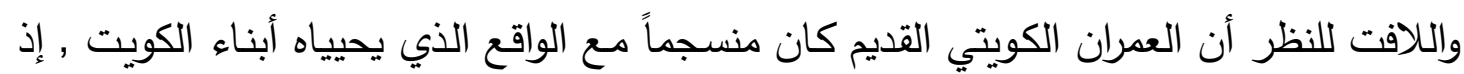

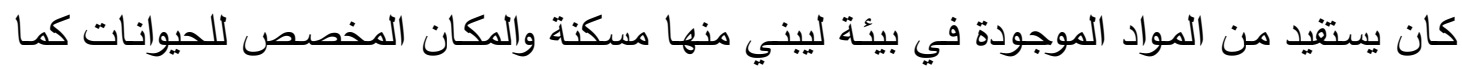
كان يكفيه ليتلاءم مع الطبيعة القاسية , إضافة إلي إضفاء جو اجتماعي مميز أسهم في تعزيز لهئي

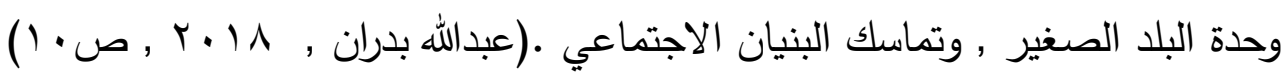

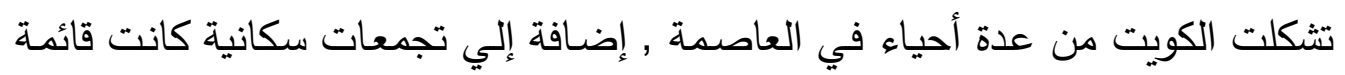

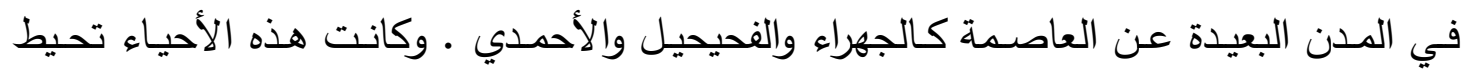
بالبحر وتقع قرب الساحل ـ وإلي جانب ذلك التكتل كانت هنالك بيوت متناثرة تقع قريبا من

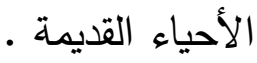


ومسن أثـهر الأحياء القديمـة حيان يعرفان بإسم (حي شرق) و(حي القبلـة) , وتأتي

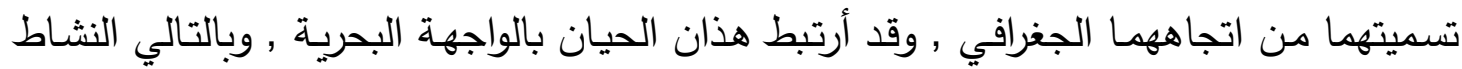

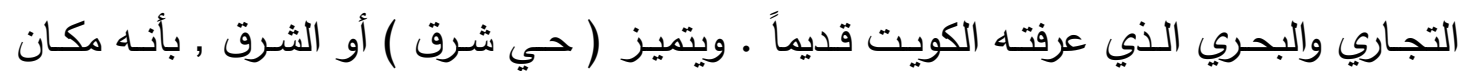

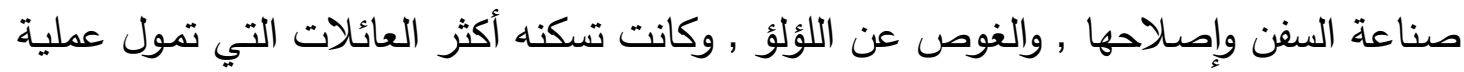

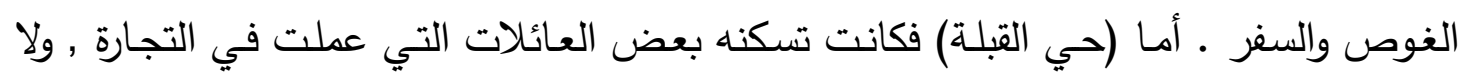
سيما تجارة الأخشاب ـ أما في الأحياء القديمة الأخري , كالمرقاب والصالحية والصفية والصوابر , فكان القاطنون بها يتميزون بممارسة عدد من المهن اليدوية إضافة إلي تجارة التجزئة .

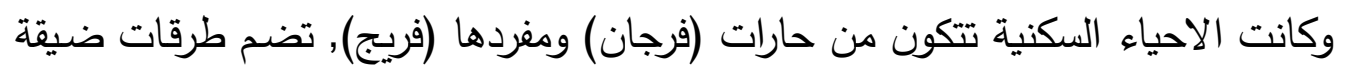

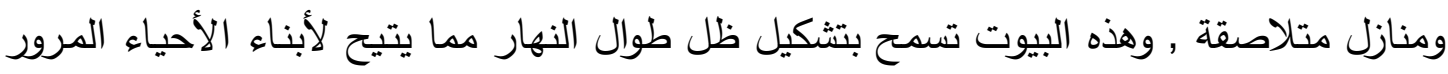

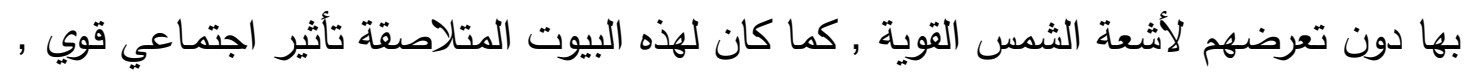

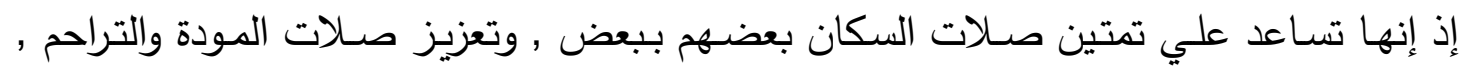

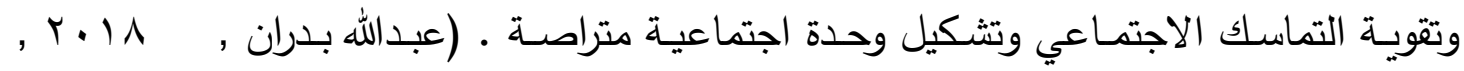

كان الكويتيون يستفيدون مما تقدمة الطبيعة لديهم من مواد للاستخدام في بناء بيوتهم ,

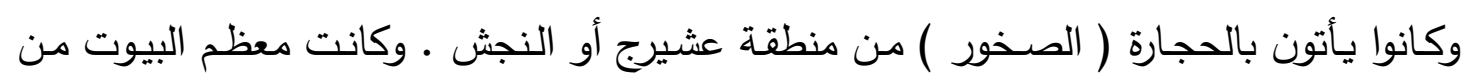

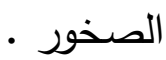

وكان الجص ( الجبس ) يستخدم لصناعة أعمدة يتراوح ارتفاعها مـا بين . (اسم و

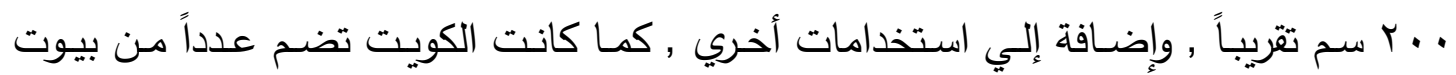
الخص (بيت الخص هو بيت من شجر أو قصب أو سعف النخيل) , وبعضها يستخدم للسكن ,

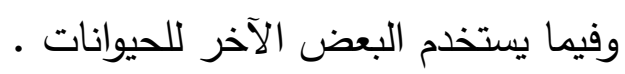

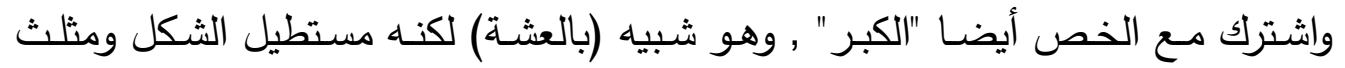

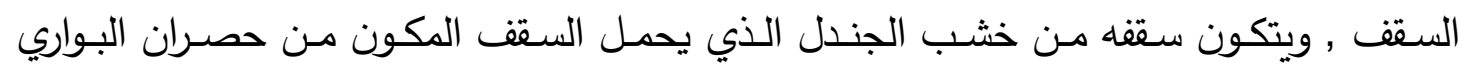
(القصب) • ثم انتشرت العشيش بعد ذلك وتطورت الالأكبار وأصبحت جدرانها من الطين .

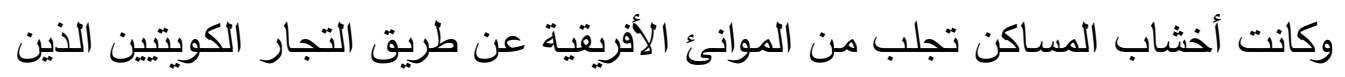

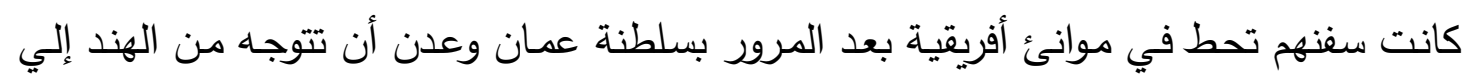

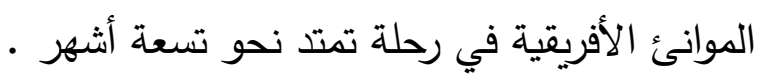




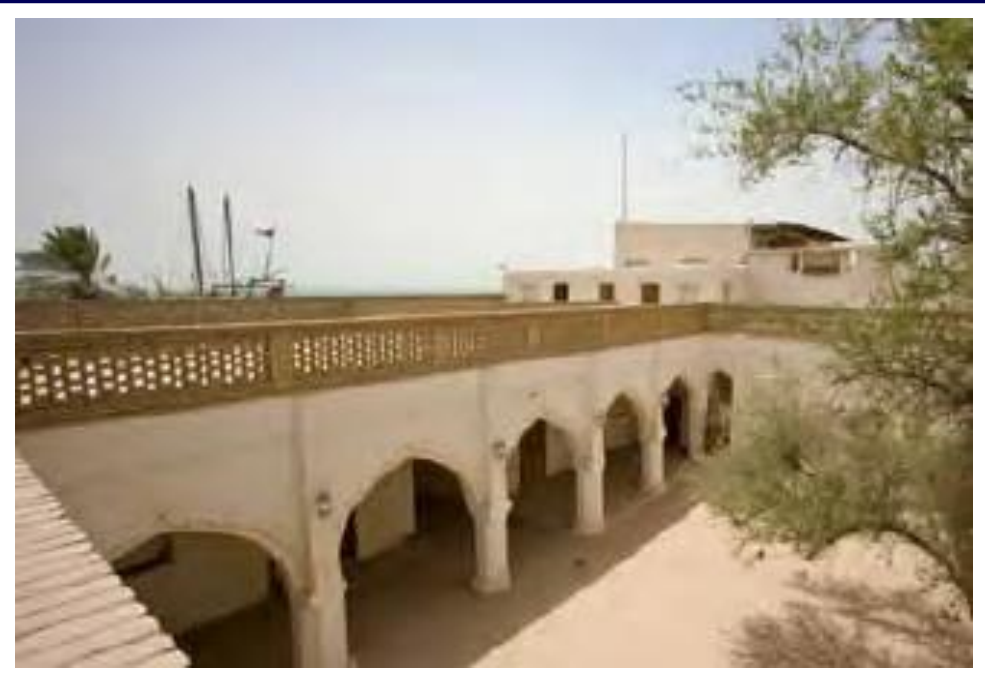

بنيت أحياء الكويت متلاصقة وفصلت بين المساكن مسافات صغيرة وكانت الأمكنة العامة التي يرتادها

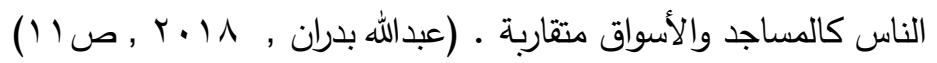

أبراج الكوبت هي ثلاثة أبراج على ساحل الخليج العربي في مدينـة الكويت في منطقة تسمى رأس عجوزة، صممت من قبل مكتب ليندستروم الهندسي في السويد ونفذت من قبل شركة انيرجوبروجيكت اليوغوسـلافية حيث تم بنائها في عـام 9 أو وتم افتتاحها رسميا في

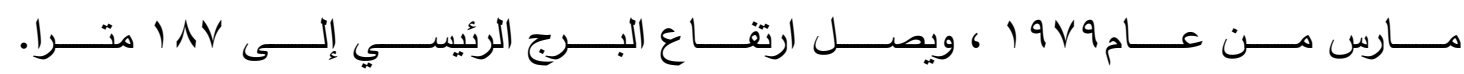
تعتبر مـن أبرز معـالم الكويـت وهي تمثل من رموز النهضـــ/(https://ar.wikipedia.org) المعاصرة ودليل تقدمها وارتقائها. في عام •،19 فازت الأبراج بجائزة آغا خان للعمارة الإسلامية، وقد شرحت اللجنة التي اختارت الأبراج ذلك بأن بناء هذه الأبراج هي محاولة دمج التقنيات الحديثة والقيم الجمالية والاحتياجات

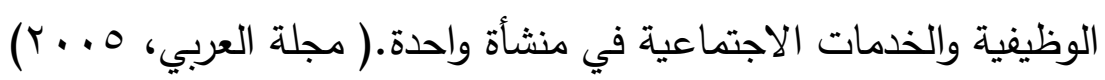

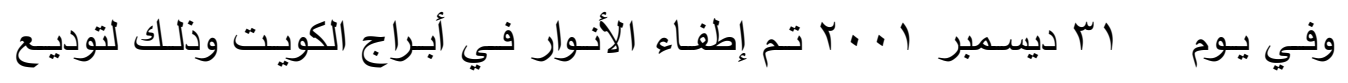

عام 1 +. الذي كانت فيه الكويت عاصمة للثقافة العربية.

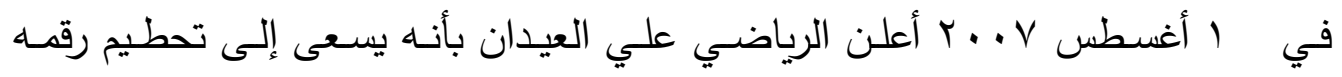

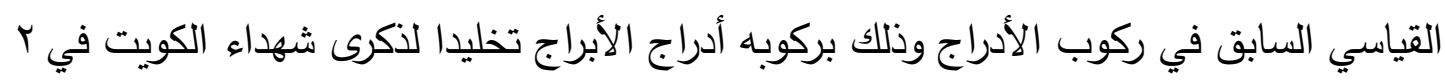

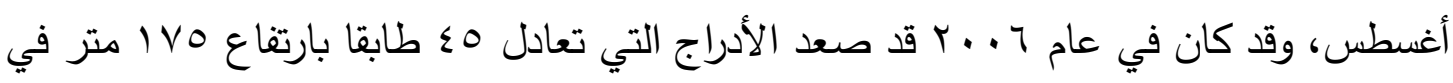
أربعة دقائق وثلاثين ثانية . 


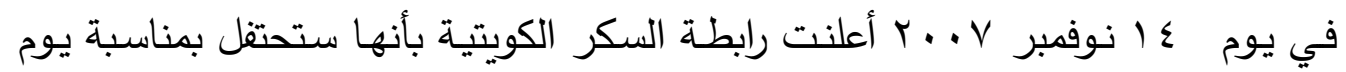
السكر العالمي بإضـاءة أبراج الكويت بمشاركة . . 1 معلم عالمي، سيتم إضـاءة الأبراج باللون

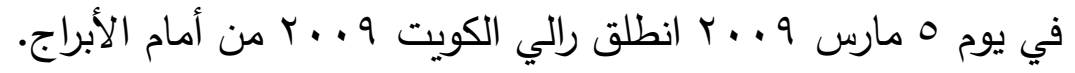

أبراج الكويت هذا المكان الأمثل والتي صدمت لتتماشى تصميمها مـع معالم الكويت التراثية فالبرج الأكبر والرئيسي والذي يحمل الكرتين يدل على " المبخر " والبرج الثاني الذي يحمل كرة واحدة يـل على "المـرش " والبرج الثالـث وهو الأصـغر يدل على " المكحلة " والصـحون التي تكسو الكـرات تبلـن عددها خمسـة وخمسـون ألف صــن وهـي مصـنوعة مـن الحديـد المطلي بالصيني بثمانية ألوان زاهية تناغما مـع السماء والبحر • وتعتبر من أهم المعالم السياحية في دولتة الكويت وهي تمثل من رموز النهضـة المعاصـرة ودليل تقدمها وإرتقائها. ( مجلة العربي،

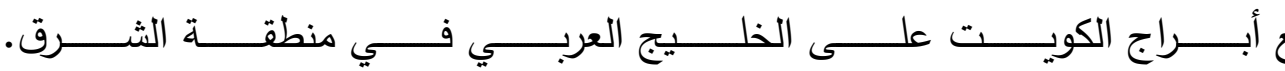

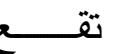

صدمت أبراج الكويت بطريقـة راقية وأنيقـة من قبل شركة سويدية ونفذت من قبل شركة يوغوسـلافية حيث تم بنائها في عام 9 أوتم افتتاحها عام 9V9 9 ميلادي.(الموقع الرسمي لأبراج الكويت)

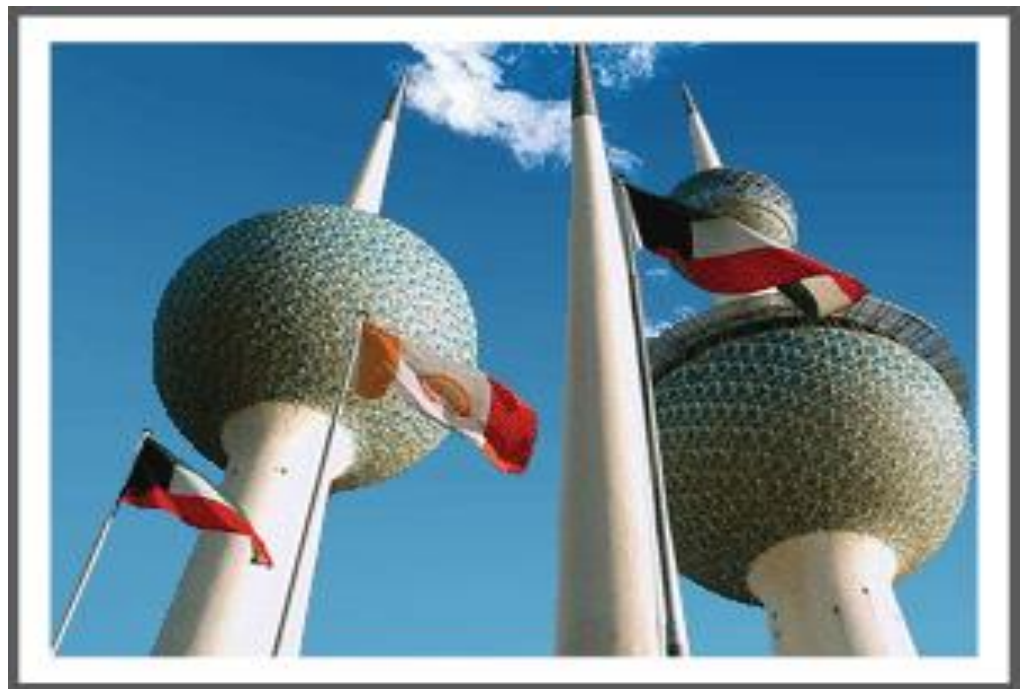

$$
\text { أبراج الكويت (الموقع الرسمي لأبراج الكويت) }
$$


ذكر ( أيوب حسين · · P) أن الفنون الثعبية الكويتية مصدر إلهام للفنانين وإبداعهم

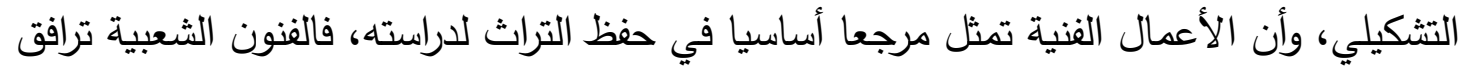

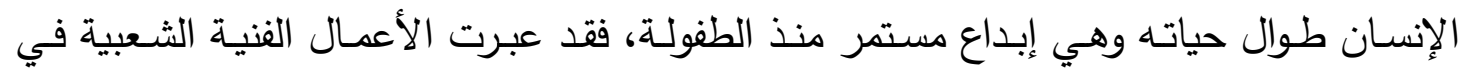

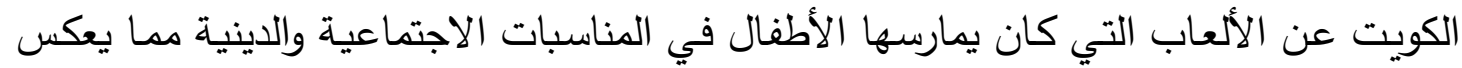

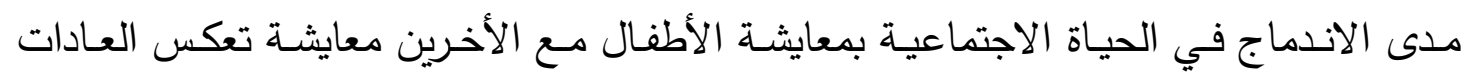

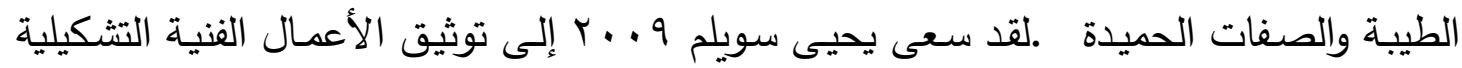

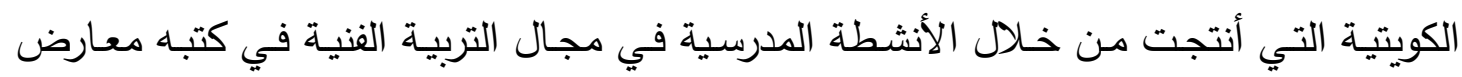
الربيع وبدايات التشكيل في الكويت.

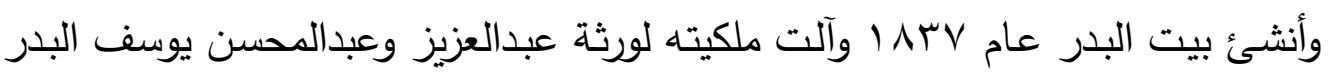

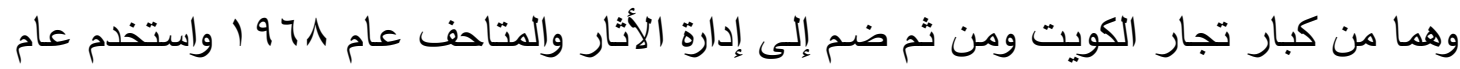

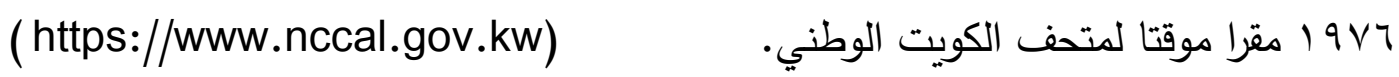

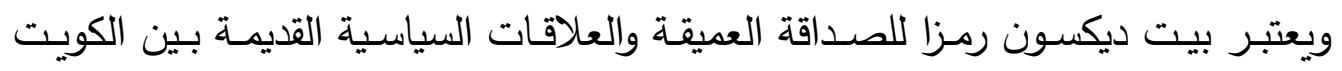
وبريطانيا والتي تمتد إلى حوالي . . . عام وأجريت عليه عدد من عمليات إعادة البناء والتأهيل تحت أشراف المجلس الوطني للثقافة والفنون والأدب وتبرع من مؤسسة الكويت للتقدم العلمي. واصبح بيت ديسكون بعد ترميمه وإعادة ملامحه المعمارية والحضـارية وبعد تحويله إلى مركز

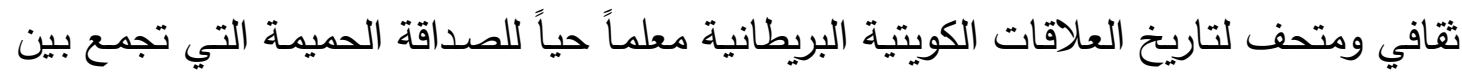
الكويت وبريطانيا.

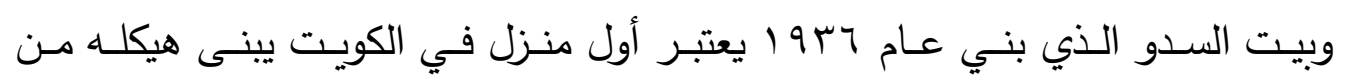

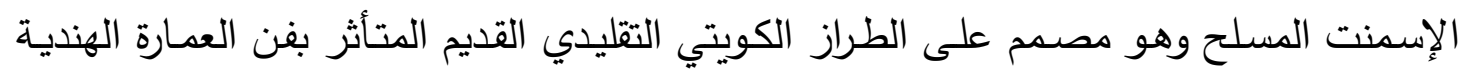
الإسلامية ويمكن ملاحظة ذلك من خلال الوحدات الحديدية الزخرفية الموجودة على نوافذ البيت. (https://www.alriyadh.com// vq) $\leqslant \varepsilon$ ) 
وسنعرض بعض الجداريات علي جدران دوله الكويت:

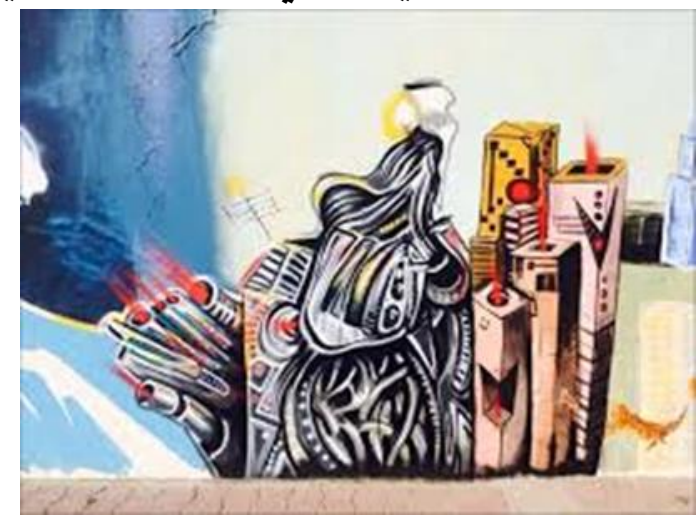

جدارية فنية للتغلب علي تشوهات جدران مدينة الكويت

(https://www.aljazeera.net/news/miscellaneous $/ r \cdot 1 \tau / r / 1 r$ )

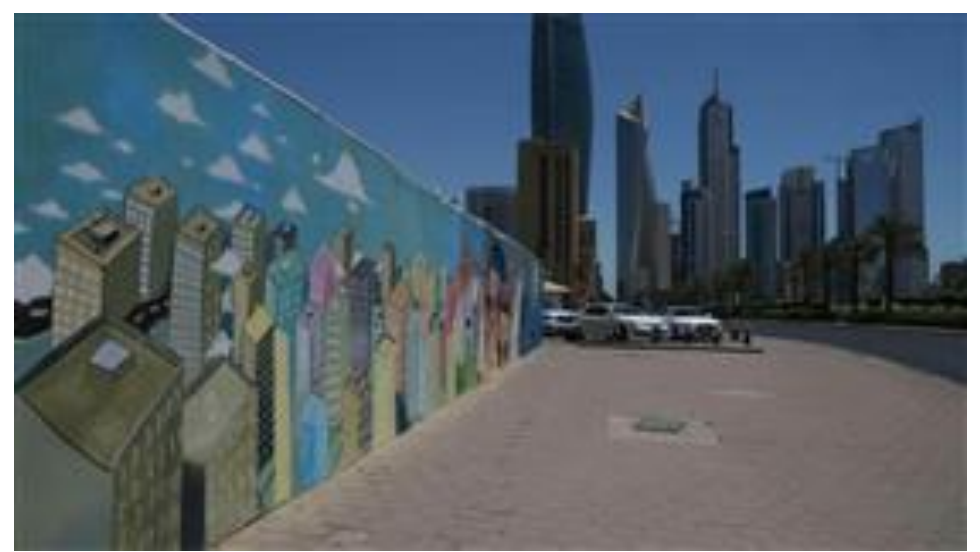

حرصا على رفع الوعي الفني للشباب وفتح الأبواب أمام أصحاب المواهب، دعا المجلس الوطني للثقافة والفنون والآداب بالتعاون مع مجموعة 》فيزول ثيربي" جمعا من الفنانين الثباب في الكويت إلى رسم لوحة جدارية على أحد جدران المجلس تبلغ مساحته ب × × • ع مترا. http://alwatan.kuwait.tt/articledetails.aspx?id= $=r \leqslant 0 \leqslant r \& y e a r q u a r t e r=r \cdot 10 r$

يهدف المشروع الى تحويل الأماكن العامـة الى لوحات تعكس متعـة بصرية تشجع على الحوار المدني، وتعزيز المهارات الابداعية للفنانين الشباب واضـافة لمسـة جمالية على الجدران الكبيرة، مما يزيد الوعي بضرورة توسيع الثقافة البصرية لجميع شرائح المجتمع الكويتي. شارك في انجاز الجداريـة ستة فنانين تعاونوا معا لاظهار مواهبهم وهم (شهد بشارة أحمد سليمان - زهرة المهدي - ثريا لين - بدور أحمد - نواف عبدالكريم) وأسهم كل منهم بثكل فريد لتنفيذ اللوحة الجدارية التي تصور طاقة الحياة المنبعثة من أرجاء المدينة منذ الثروق حتى 


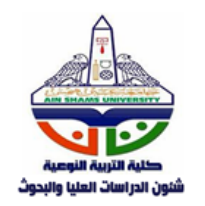

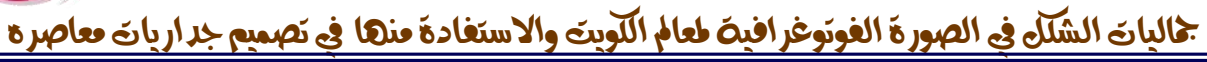

الغروب، حيث يتم تصور مدينة الكويت بتتوع شخصياتها، وقد اختار كل فنان شخصيات مختلفة من المجتمع.

ومن المقرر ان تعرض الجداريـة المنفذة للجمهور على مدى أربعة شهور ، تتم بعد ذلك

ازالتها تمهيدا لتتفيذ جدارية اخرى، وهكذا، تتعاقب الجداريات بصورة فصلية.
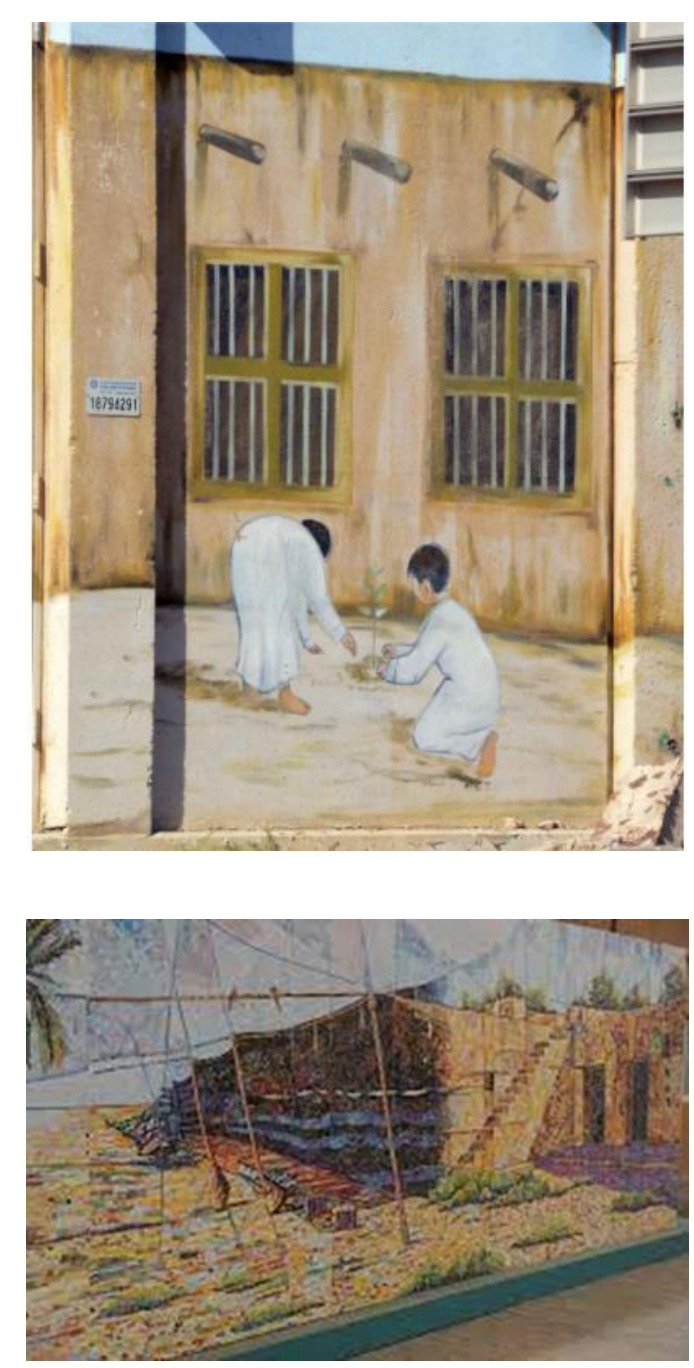

إضفاء تعابير مستوحاه من تاريخ الآباء والأجداد ذات المعاني القيمة عند الكويتيين علي محولات

الكهرباء في مختلف مناطق البلاد .

( kuna.net.kw/ArticleDetails.aspx?id=rт7०91 ८\&language=ar) 
وهناك الكثير من البرامج الحاسوبية التي يستعين بها الفنان والمصمم سواء على مستوى

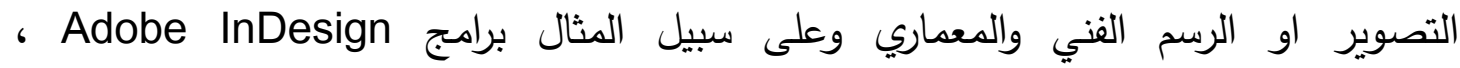
Ucancam CCorel draw ، photoshop

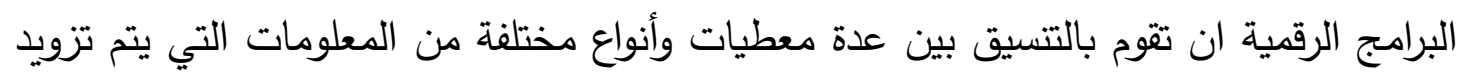

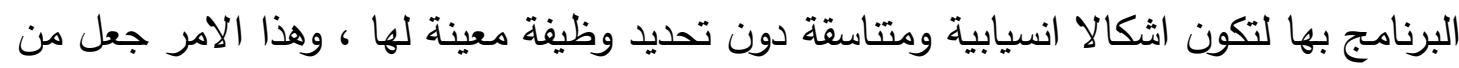
الممكن خلق اثكالا عضوية وديناميكية بطريقة منظمة ومحكمة مما ساعد في نقل هذه الأفكار

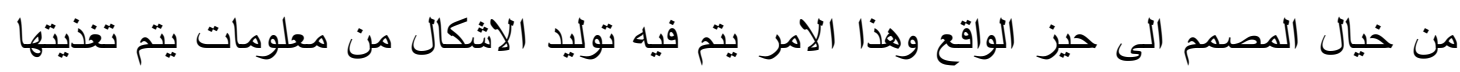
للبرامج ومن ثم تحويلها الى معادلات او خوارزميات تتحول الى لغة الحاسوب الرقمية لكي يتم

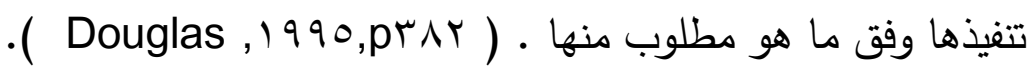

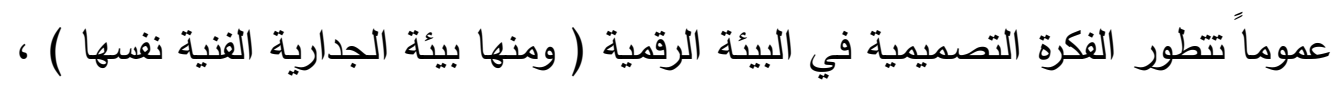

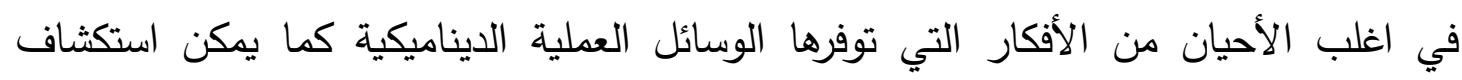
العلاقة بين التلاعب التكتيكي بواسطة الحاسوب (والتي سهلت باستخدام البرامج الجديدة) وبين

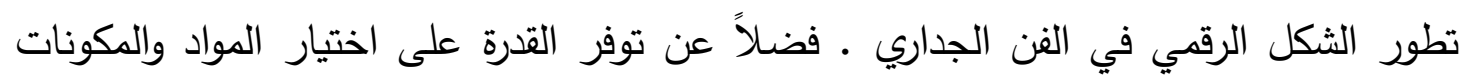

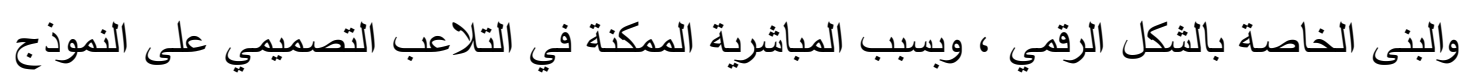

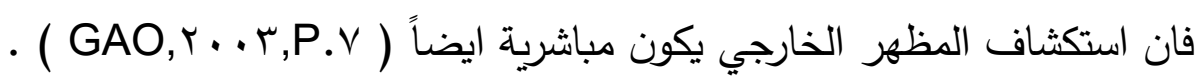
ونعرض فيما يلي أعمال الباحثة لبعض الجداريات تميز العمل الفني بتنوع جماليات التيات

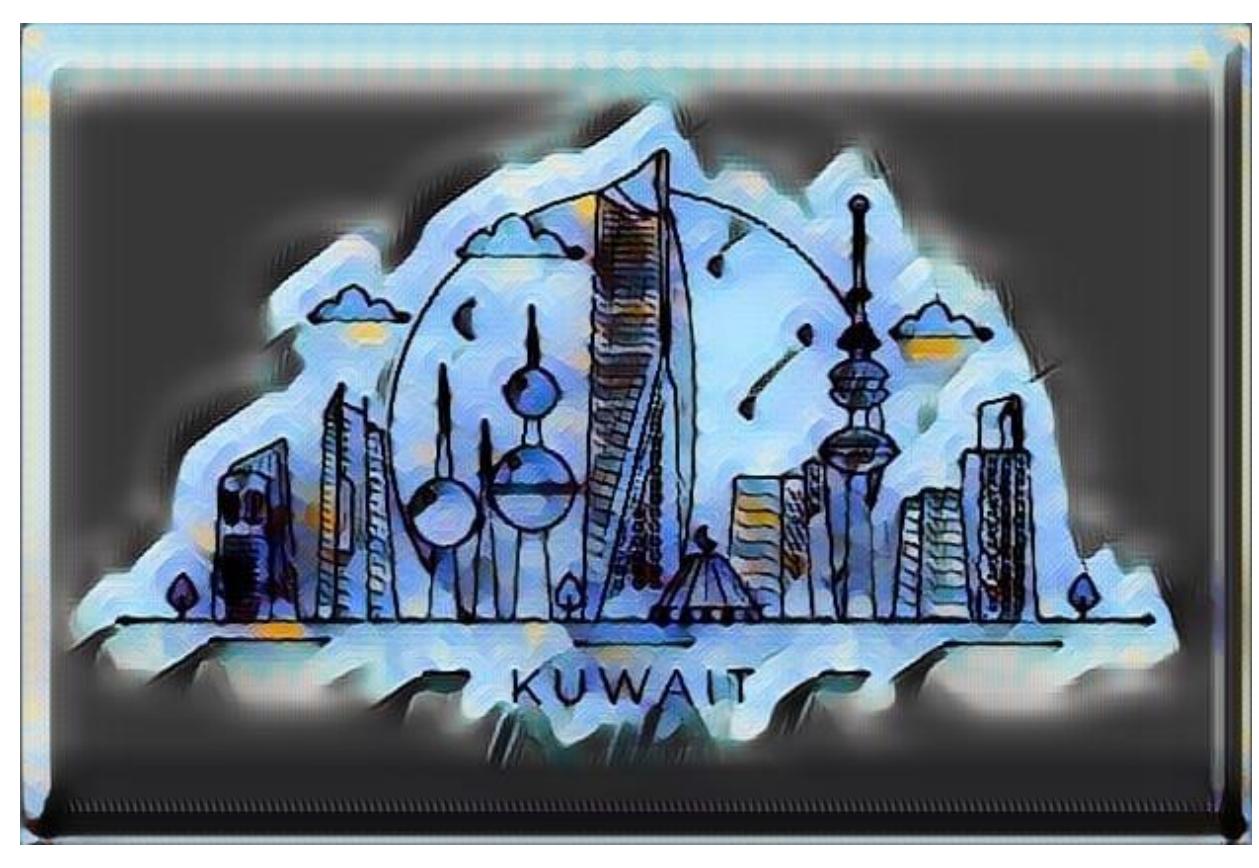

العمارة الكويتية و و ذلك التنوع مظاهره و مروره بأكثر من طبيعة وبيئة فالطبيعة الكويتية لها جماليات 
خاصه. مما يظهر في التصميم انعكاس الأثكال المتكسرة علي الأمواج تضفي إحساسا باستقرار الأشكال... والاتزان وهو من جماليات بيئة الكويت كما تختلف تلك الجماليات باختلاف أوقات اليوم كما يوضح في التصميم ... فإن منظر الليل وتأثيراتها اللونين وانعكاساتها علي المياه تمثل قيمة جمالية مختلفة وغنيه بالمثيرات الثمالية التي تتضمنها بيئة الكويت .... كما يمثل دلالات رمزيه راسخه في الثقافة الكويتية بما يمثله كمصدر للحياة والاستقرار ....

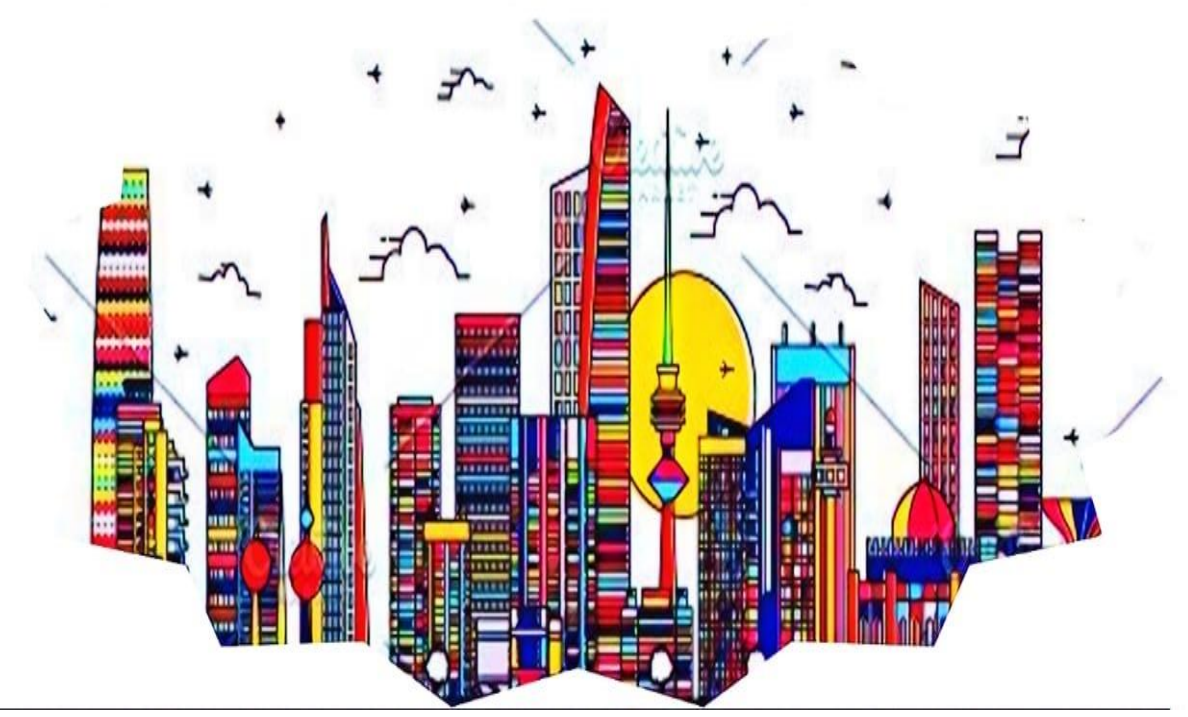

تناولت الباحثة في هذا العمل معالم الكويت مستخدمة برامج الحاسب في إضفاء بعض الفلاتر والألوان الزاهية لإبراز جماليات الثكل للعمارة الكويتية مع مراعاة أسس التكوين الجيا من نسبة وتناسب وإيقاع واتتزان

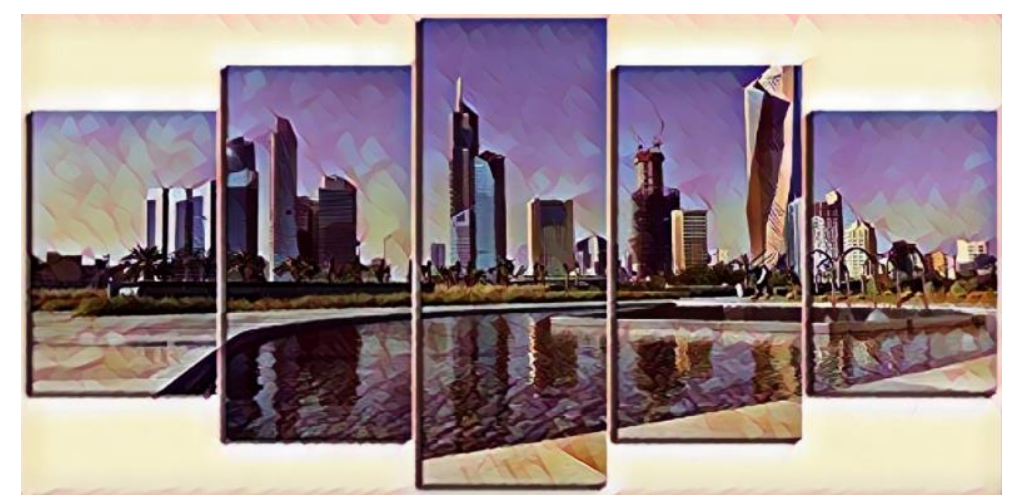




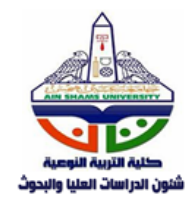

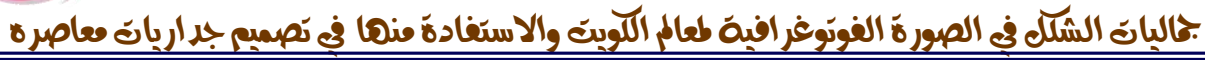

تتاولت الباحثة البيئة الكويتية بالتحوير والتبديل والتغير سعيا وراء ما يوحي بحقيقه تلك الأشكال... فيظهر في العمل الفني معالجه للأشكال والخطوط والألوان المرسومة إلا إنها كانت تهدف إلي ربط الفن بالهيئة الكويتية..

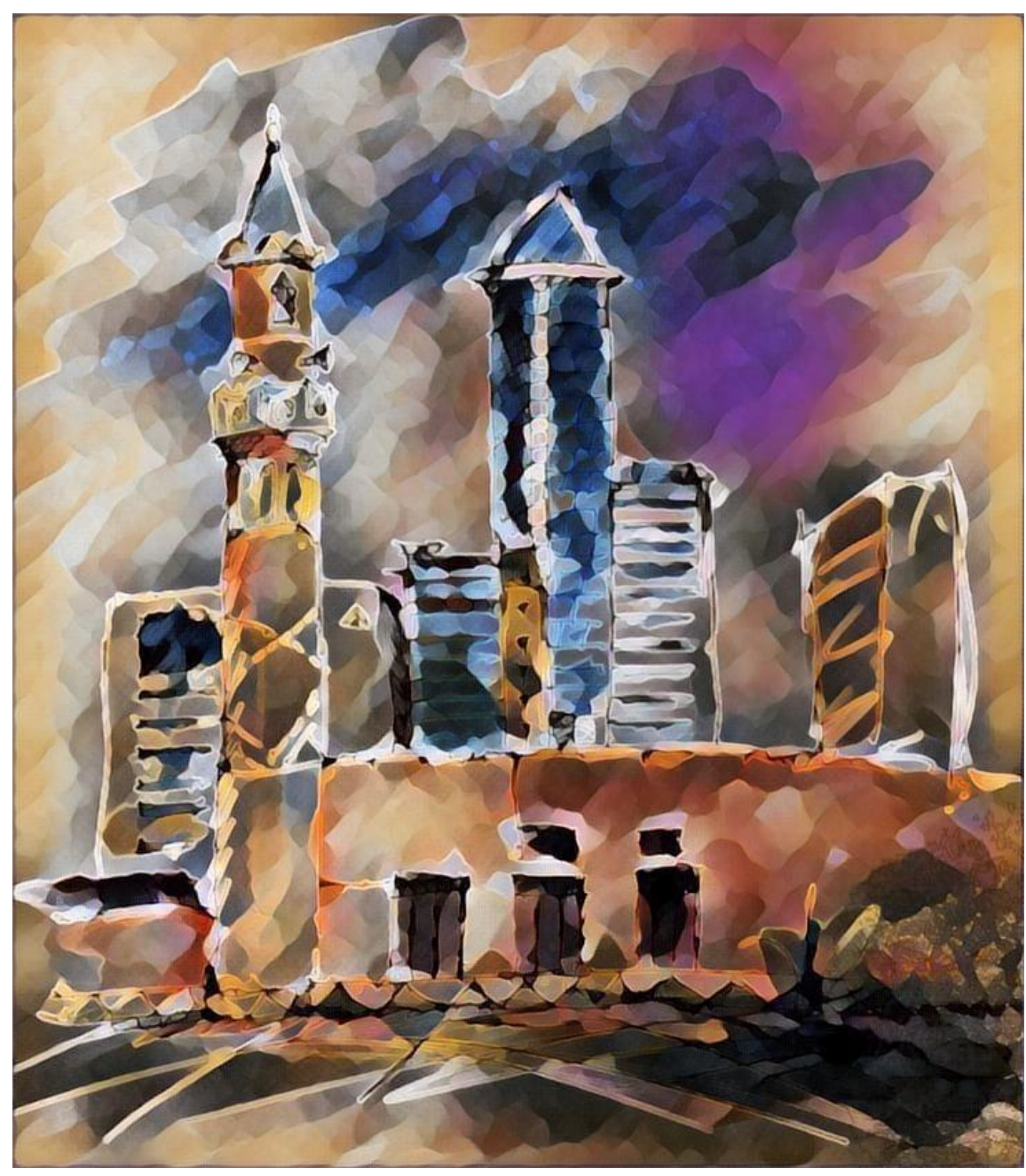

تناولت الباحثه من خلال استخدام الصور الفوتوغرافيه اهم معالم الكويت مما قدم لنا تجربه جديده في التصميم ..حيث سجل انطباعات خطيه ولونيه حيال الثوارع والعماره الكويتيه.

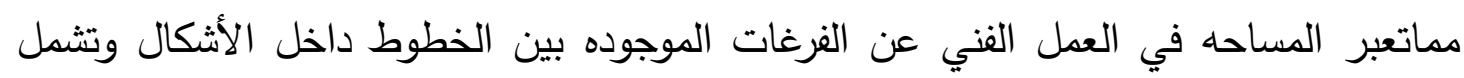

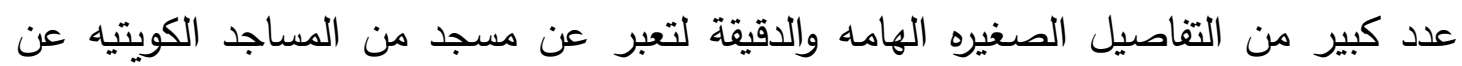

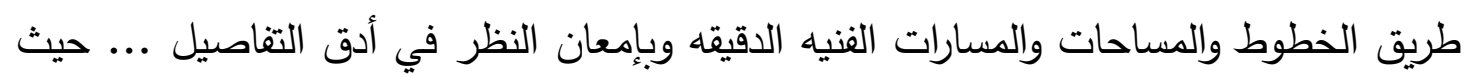
يعتمد العمل الفني علي احجامها من ناحيه الصغر والكبر والنسب مابين الاشكال بعضها

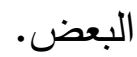




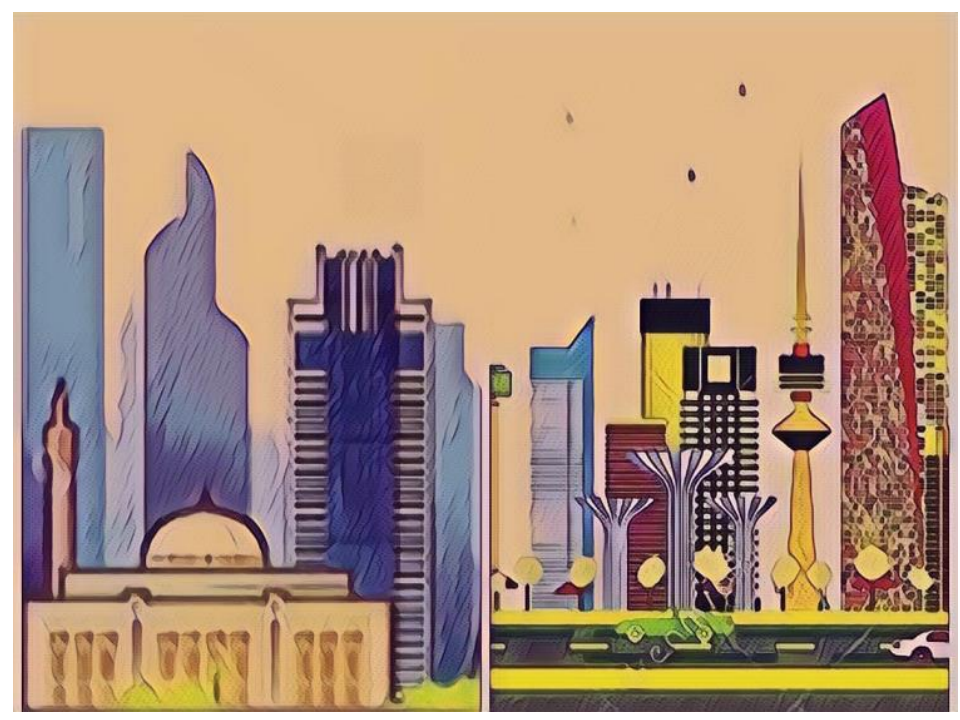

يتتاول العمل الفني اهم معالم العمارة الكويتية بمختلف الأحجام والأطوال ؛حيث قامت الباحثة بتذخل الأشكال الهندسية فوق بعضها ليحقق من خلالها الظل والنور خلال الألوان والإضاءة الساقطة علي العمل • حقق الإيقاع اللوني بالملامس والمساحة الواسعة للتكوين مما يزيد من دقه وبسيطة التكوين الفني ..

تاسعاً : النتائج والتوصيات:نتائج البحث:

كثفت الدراسة في البحث الحالي عدة نتائج يمكن إيجازها فيما يلي:

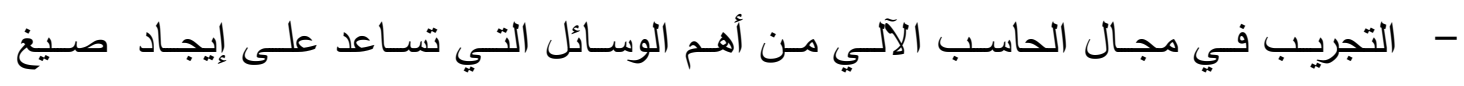
لتصميمات جدارية معاصرة.

- أهمية الصورة الفوتوغرافية في إبداع تصميمات فنية لجداريات معاصرة . - أمكن توفير الجهد والمال وخلق تصميمات جدارية اكثر دقة .

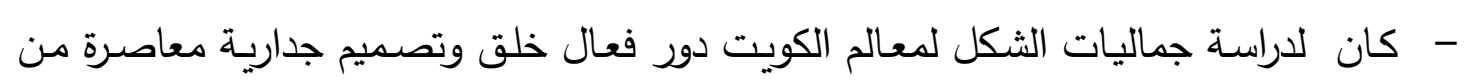
خلال برنامج الفوتوشوب. • يمكن إيجاز ما يوصي به الباحث فيما يلي: - - الحث على ممارسة التجريب بشكل مستمر في برامج الحاسب التقليدية والمستحدثة مما يتيح الفرصة لفتح منطلقات جديدة لحل مشكلات التصميم الجداري. 


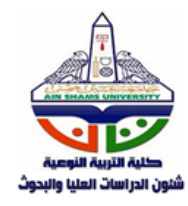

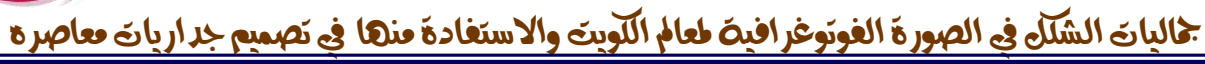

- الاهتمام بدراسة البرامج الفنية الحديثة لفتح أفاق أوسع للطلاقة الفكرية للابتكار والتجديد في مجال الفن التثكيلي. - - ضـرورة الاستزادة من الأبحاث التي تتـاول برامج الحاسب الجديدة للكثف عن إمكانات تثكيلية مبتكرة في مجال التصميم الجداري .

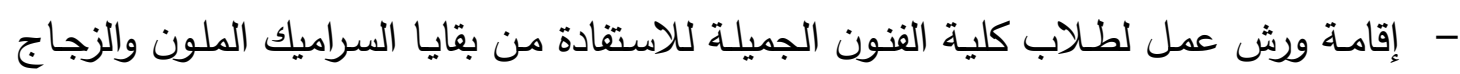
والأحجار وخامة ألوان الأكريليك للمشاركة في تنفيذ لوحات جداريـة على الحوائط الخارجية لمباني الجامعة.

- الاطلاع على التقنيات الرقمية الحديثة ومواكبة تطورها وبما يدعم عملهم في الجانب الفني التصميمي والتشكيلي. 


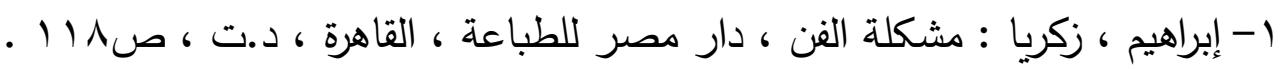

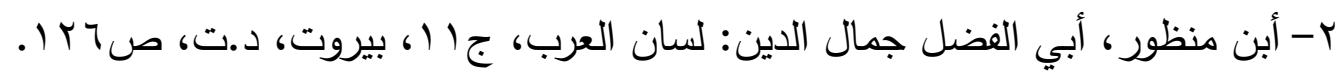

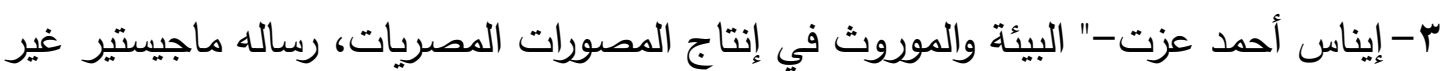

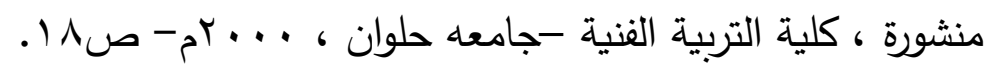

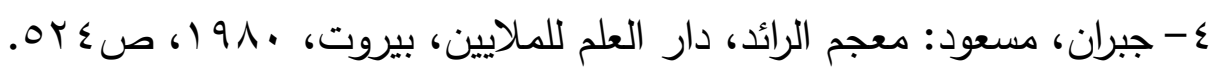

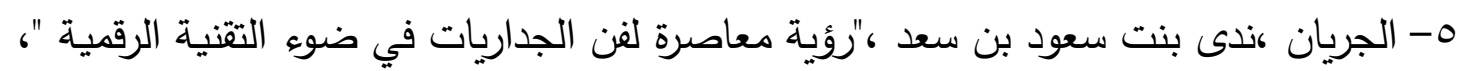

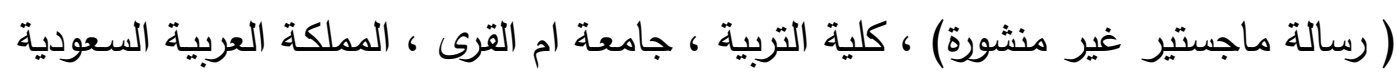
.$\mu \cdot \mu_{6}$

צ- جورج سانتيانا : الإحساس بالجمال، تخطيط لنظرية في علم الجمال، ترجمة مصطفى بدوي،

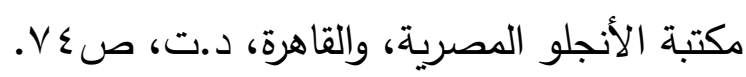

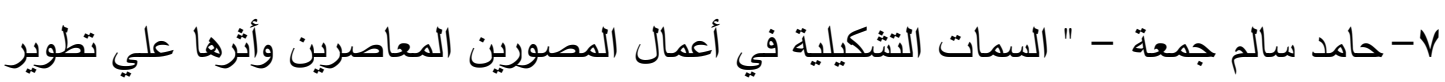

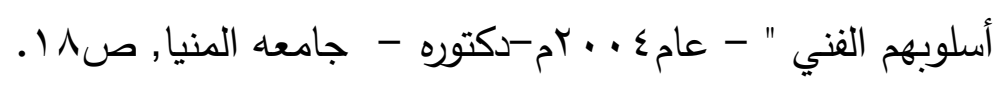

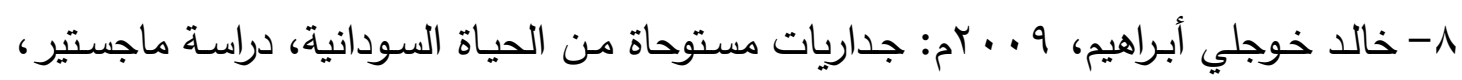
جامعة السودان، كلية الفنون الجميلة والتطبيقية.

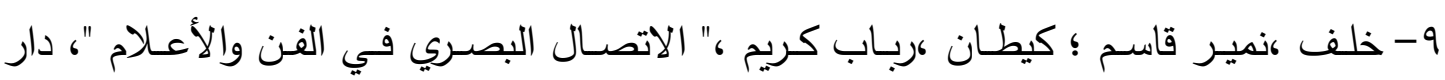

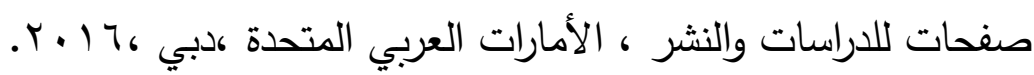

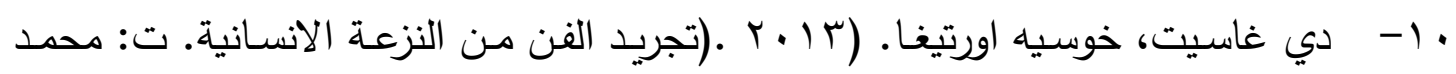

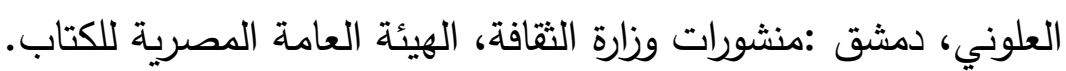

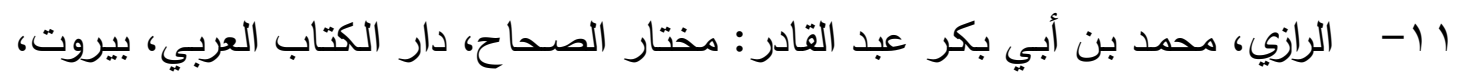
- n

r با - الزاوي، الطاهر أحمد: ترتيب القاموس المحيط،ط مجمع اللغة العربية ، القاهرة، د ـ ت الت

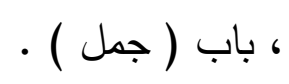

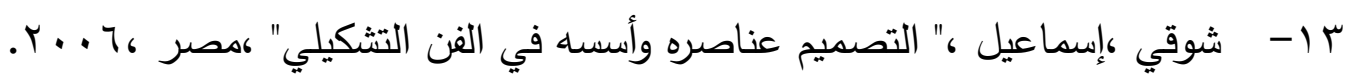

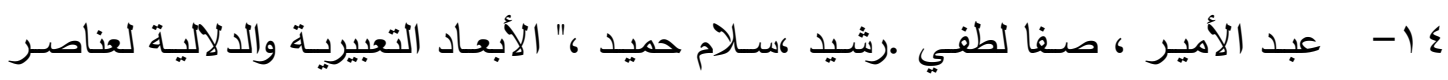

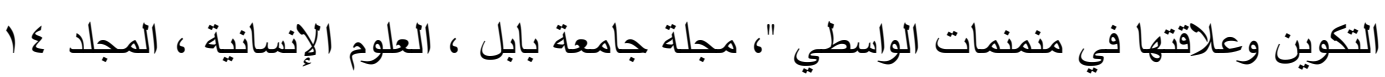

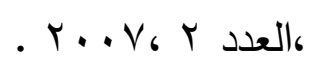


10- عبد الحميـد، شـاكر : التفضـيل الجمـالي، المجلس الـوطني للثقافـة والفنـون والآداب،

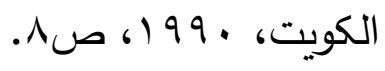

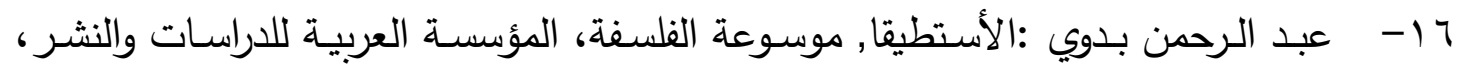

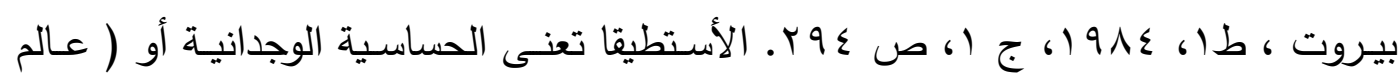
الأحاسيس المعرفة الحسية) أما المعنى الإصطلاحى فهو الدراسة العلمية للنشاط الجمالي

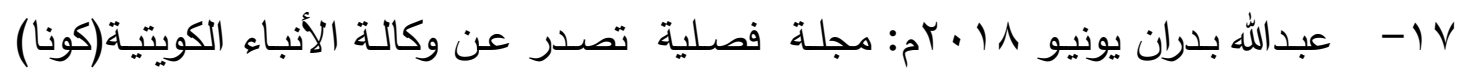

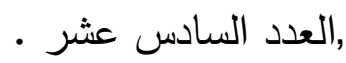

11- عز الدين إسماعيل: الأسس الجمالية في النقد العربي، عرض وتفسير ومقارنة، دار

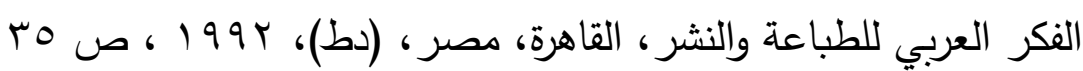

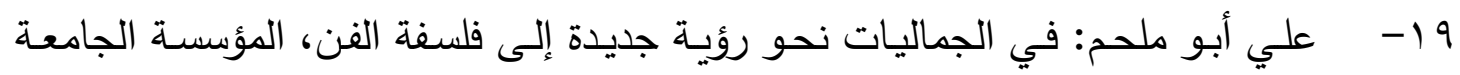

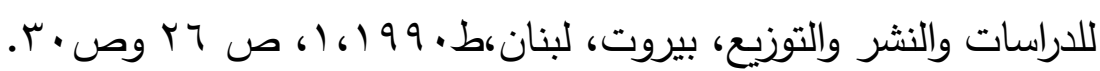

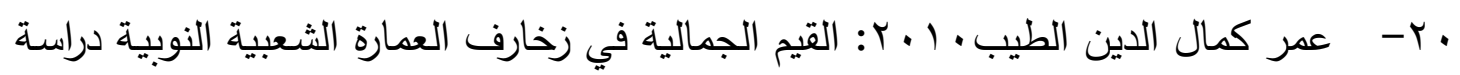
ماجستير , جامعة السودان للعلوم والتكنولوجيا، كلية الفنون الجميلة والتطبيقية.

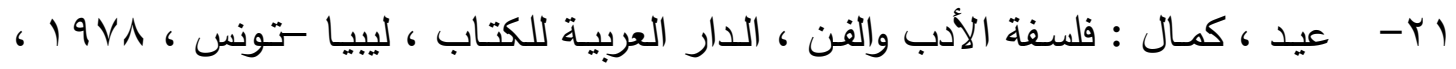

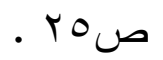

r ب- عيد ،أمجد عبد السلام ، " الفن الرقمي كوسيط تقني لأثراء التصميم التشكيلي وأثره على التى

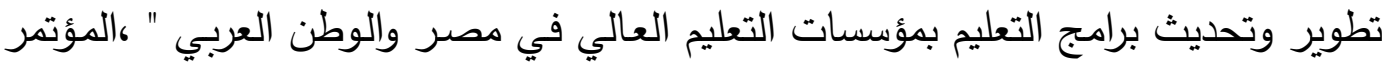

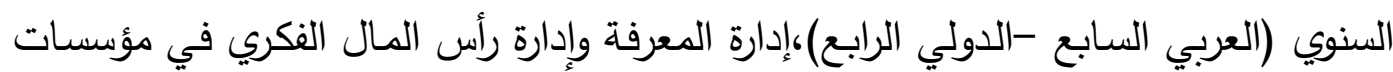

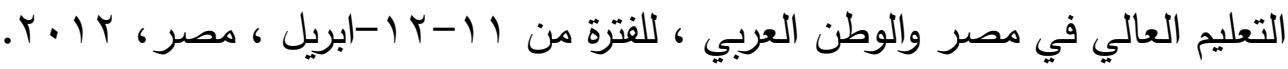

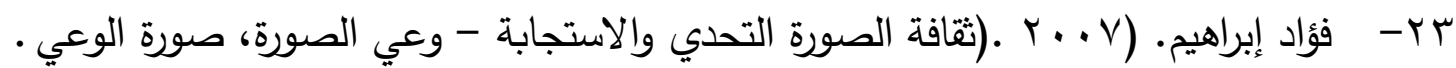
المؤتمر الدولي الثاني عشر، فيلادلفيا.

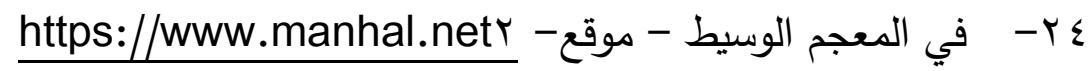

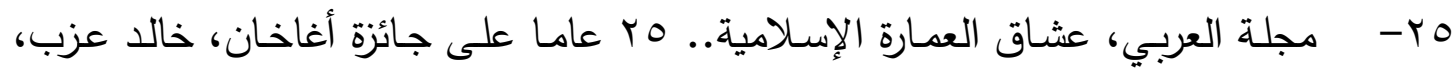

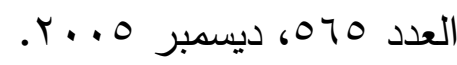

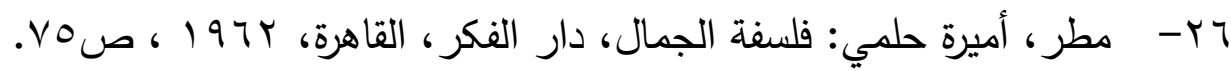

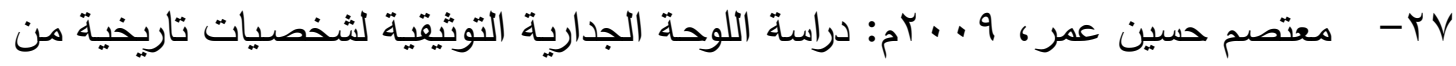
أم ادرمان، دراسة ماجستير ، جامعة السودان، كلية الفنون الجميلة والتطبيقية. 
^ץ- - معتوق ، محمد محمود حسن ،" الأبداع الفني في بيئة الوسائط الرقمية كموجـه لتطوير التعليم والتدريب المعماري في المستقبل "، المؤتمر القومي السنوي العاشر ، العربي الثاني

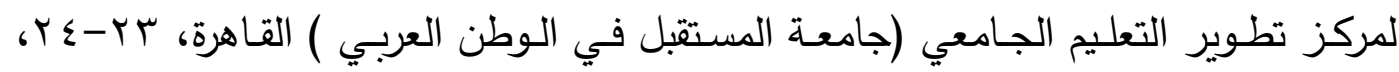

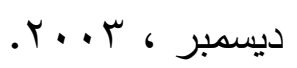

9 (-http://kuwaittowers.com) الموقع الرسمي لأبراج الكويت

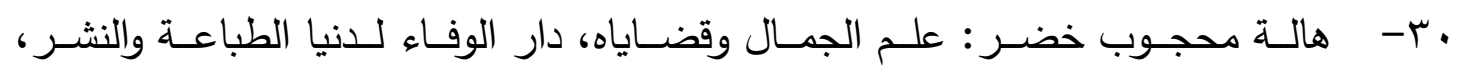

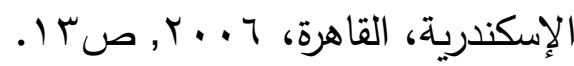

r)- Douglas Davis, "The Work of Art in the Age of Digital Reproduction (An Evolving Thesis :1991-1990)", Leonardo ,Vol.r^,No.॰,Third Annua; New York Digital Salon .(1990),pp.r^พ人т.

rr- GAO,WAN-PING, “ Graduate Institute of architecture ,National Chiao -Tung University , r..r.

rr- https://www.alriyadh.com//vq) $\varepsilon \varepsilon$

rs- https://www.nccal.gov.kw/pages/monumentsandmuseums/\%D^\%A

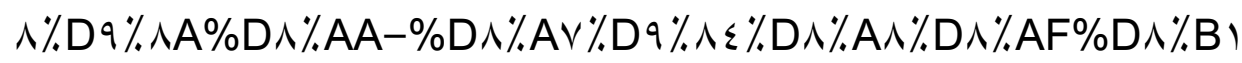

ro- kuna.net.kw/ArticleDetails.aspx?id=rq 